Matthias Linnemann, Klaus-Peter Priebe, André Heim, Carsten Wolff, Jadran Vrabec

\title{
Experimental investigation of a cascaded organic Rankine cycle plant for the utilization of waste heat at high and low temperature levels
}

Journal article | Accepted manuscript (Postprint)

This version is available at https://doi.org/10.14279/depositonce-9847

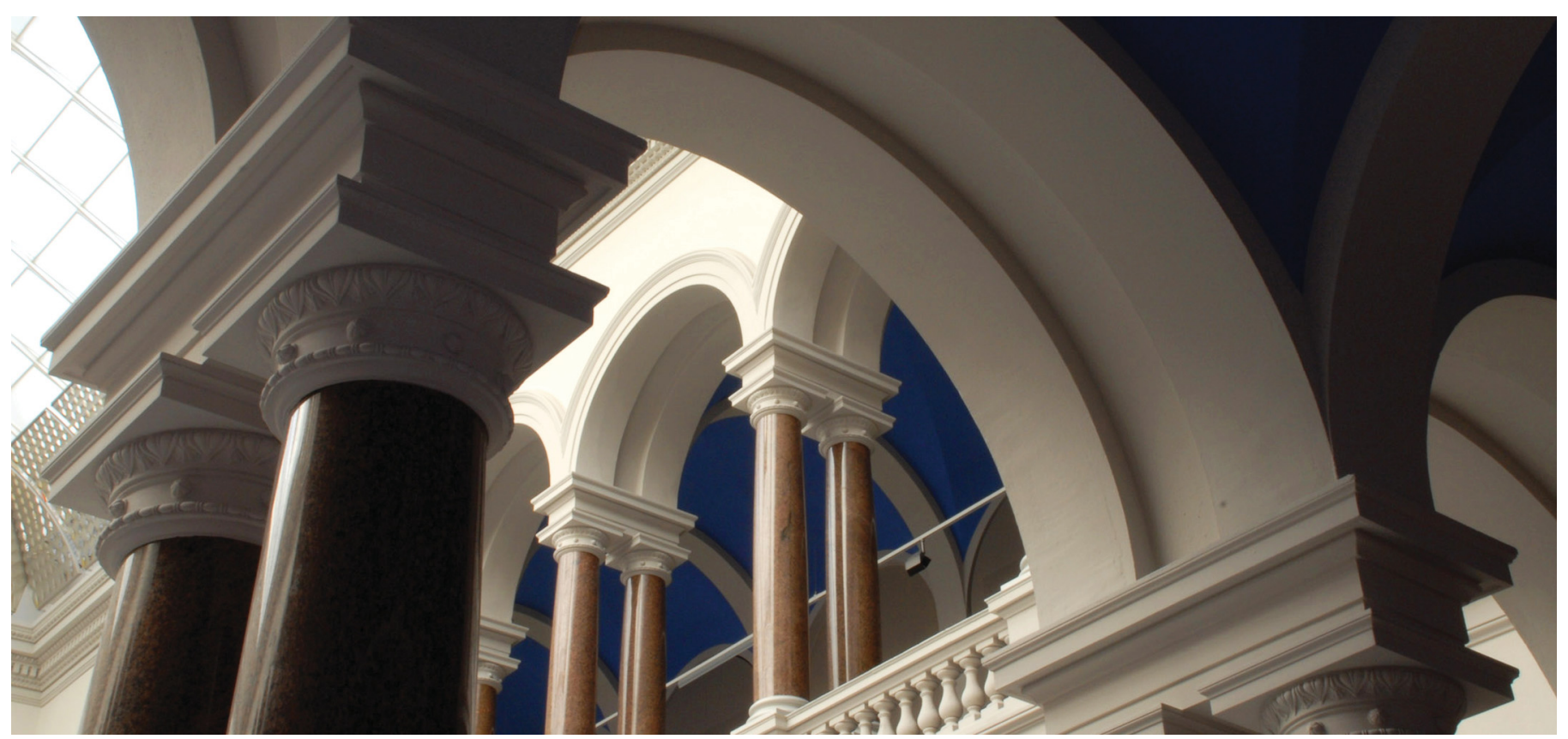

Linnemann, M., Priebe, K.-P., Heim, A., Wolff, C., \& Vrabec, J. (2020). Experimental investigation of a cascaded organic Rankine cycle plant for the utilization of waste heat at high and low temperature levels. Energy Conversion and Management, 205, 112381. https://doi.org/10.1016/j.enconman.2019.112381 
Accepted manuscript of: Linnemann, M., Priebe, K.-P., Heim, A., Wolff, C., \& Vrabec, J. (2020). Experimental investigation of a cascaded organic Rankine cycle plant for the utilization of waste heat at high and low temperature levels. Energy Conversion and Management, 205, 112381. https://doi.org/10.1016/j.enconman.2019.112381

(C) 2019 This manuscript version is made available under the CC-BY-NC-ND 4.0 license https://creativecommons.org/licenses/by-nc-nd/4.0/

\title{
Experimental investigation of a cascaded organic Rankine cycle plant for the utilization of waste heat at high and low temperature levels
}

\author{
Matthias Linnemann ${ }^{\mathrm{a}}$, Klaus-Peter Priebe ${ }^{\mathrm{b}}$, André Heim ${ }^{\mathrm{c}}$, Carsten Wolff ${ }^{\mathrm{b}}$, \\ Jadran Vrabec ${ }^{\mathrm{a}, *}$ \\ ${ }^{a}$ Thermodynamics and Process Engineering, Technical University of Berlin, \\ Ernst-Reuter-Platz 1, 10623 Berlin, Germany \\ ${ }^{b}$ Dortmund University of Applied Sciences and Arts, Otto-Hahn-Straße 23, 44227 \\ Dortmund, Germany \\ ${ }^{c}$ Heim Präzisionstechnik GmbH, Höfenstraße 6, 51645 Gummersbach, Germany
}

\begin{abstract}
A power plant with two cascaded organic Rankine cycles (CORC) to exploit waste heat from a $800 \mathrm{kWe}$ combined heat and power plant, fueled by biogas, is designed and tested. Heat from the exhaust gas is utilized with a high temperature organic Rankine cycle (HT-ORC), where toluene is employed as a working fluid. The heat discharged from the HT-ORC as well as heat from the engine coolant and additional heat from the exhaust gas is supplied to a low temperature ORC (LT-ORC) with the working fluid Solkatherm SES36. The design of the CORC and the selection of working fluids is presented, aiming at a maximum plant efficiency, but also complying with environmental, safety and practical issues. Furthermore, plant components and construction details are described. After manufacturing, initial tests are carried out, obtaining thermodynamic conditions that are close to the design of the HT-ORC, where a maximum electrical turbo-generator output of $17.5 \mathrm{~kW}$ is measured. The cascading of the low temperature heat sources and the transfer to the LT-ORC is shown as well as the basic operation of the LTORC. However, several problems occurred, such as a turbo-generator damage in the HT-ORC, a too high condensation pressure and a low working fluid mass flow rate in the LT-ORC, which are discussed together with proposed
\end{abstract}

\footnotetext{
${ }^{*}$ Corresponding author

Email address: vrabec@tu-berlin.de (Jadran Vrabec)
} 
optimization measures.

Keywords: Organic Rankine cycle (ORC), Cascaded ORC (CORC), Dual loop ORC (DORC), Waste heat recovery

\section{Introduction}

Reducing fossil fuel consumption and implementing a sustainable energy supply is essential for mitigating climate change [1]. In order to meet this challenge, the utilization of renewable energy sources must be increased as well as the energy efficiency of industrial processes, vehicles, power generation and heating systems. In this context, the exploitation of waste heat offers a large potential for savings. Waste heat recovery (WHR) is particularly promising for the industry, where $20-50 \%$ of the energy consumption is wasted as unused heat $[2,3]$. This also holds for internal combustion engines (ICE), where $55-80 \%$ of the fuel's energy is converted to heat that is mainly discharged to the environment [4]. Next to the use of waste heat for secondary processes or district heating, another promising approach is the generation of power from heat, where the organic Rankine cycle (ORC) is known as an efficient technology. Based on the classic steam Rankine cycle (RC), other working fluids than water are employed in ORC, allowing for a wide application range in terms of the heat source temperature level. Despite the fact that the first commercial ORC plant became available already in 1952 [5] and medium and large scale ORC power plants have become state of the art and reached market maturity [6], ORC technology is still subject of numerous recent publications that aim at the increase of system performance. The focus

of research work lies on the cycle design, the selection and development of working fluids and the investigation of expanders to achieve a maximum efficiency $[7,8,9]$. In the present decade, novel ORC architectures are discussed that allow for the utilization of heat sources at different temperature levels, where a typical application is the waste heat recovery of ICE that provide a high temperature heat source through the exhaust gas $\left(480-520^{\circ} \mathrm{C}\right)$ and a low temperature heat source through the engine coolant $\left(80-90^{\circ} \mathrm{C}\right)$. In this context, reviews by Shi et al. [10] and Mahmoudi et al. [11] showed that architectures with two cascaded ORC (CORC) are particularly suitable and lead a higher net power and thermal efficiency than conventional single loop ORC. A CORC plant exploits the exhaust gas heat with a high temperature ORC (HT-ORC), while a low temperature ORC (LT-ORC) is driven by the 
engine coolant heat, residual exhaust gas heat and condensation heat from the HT-ORC.

Wang et al. [12] presented a theoretical study about a CORC system for the waste heat recovery of a $130 \mathrm{~kW}$ gasoline engine using R245fa as a working fluid for the HT-ORC and R134a for the LT-ORC. The maximum net power output of the CORC was $36 \mathrm{~kW}$, which increased the overall power output by $27 \%$ compared to the engine without a WHR system. A research group led by Shu investigated the CORC extensively and presented different cycle modes and suitable working fluid pairs, where a diesel engine with a power output of about $240 \mathrm{~kW}$ was considered as the heat source [13, 14, 15]. It was shown that a transcritical CORC with toluene and R143a as working fluids for the HT and LT loop, respectively, led to the highest calculated net power output of $42.5 \mathrm{~kW}$. This was found to be superior to a RC combined with a LT-ORC $(40 \mathrm{~kW})$, as well as to a $\mathrm{CO}_{2}$ Brayton-ORC system and a thermoelectric generator-ORC system. The group around Shu also provided an experimental work [16] about a cascaded RC-ORC system for the WHR of a $243 \mathrm{~kW}$ diesel engine, where R123 was taken as the working fluid in the LT-ORC. Valves were employed instead of turbines so that a possible power output of $12.7 \mathrm{~kW}$ was estimated for the test rig. Another experimental RCORC system with ethanol as a working fluid in the LT-ORC was described by the automobile manufacturer BMW [17], where an additional power output of about $14 \%$ was stated. However, in a subsequent development BMW focused on a single loop ORC because of its lower complexity and size [18]. Furthermore, a proof of concept for a CORC plant was laid out in a preceding experimental work of our group [19] with a laboratory scale test rig, where cyclopentane and propane were selected as working fluids in the HT- and LT-ORC, respectively. In conclusion, the few experimental investigations of the CORC system showed that there is a notable increase of complexity in operating such an advanced plant in comparison with a conventional ORC and that this promising design is not mature yet.

To achieve progress in this technology, a full scale CORC plant was designed, built and field tested in this work, where a biogas combined heat and power plant (CHP) with a maximum electrical power output of $800 \mathrm{~kW}$ provided waste heat through the exhaust gas and the engine coolant. Its thermodynamic cycle design and the selection of working fluids is described, not only focusing a high thermal efficiency and power output, but also considering environmental, safety and practical aspects. The CORC plant is presented with its components, including instrumentation, data acquisition 
and safety systems. Subsequently, the operational characteristics and the achieved performances are shown and compared with the design data. Furthermore, problems that have occurred are discussed and potential improvements are identified.

\section{Cascaded ORC design}

As a first step of the CORC plant design, the heat source was analyzed by considering its temperature levels, heat loads and thermodynamic properties of the fluids. Furthermore, the CORC must not interfere the operation of coupled processes, i.e. the ICE and the district heating network. Subsequently, the plant architecture was modeled, which was an accompanying process with the working fluid selection. Considering several cycle designs and working fluids led to an optimal plant efficiency. For clarity, the cycle architecture of the present work is described before the investigation of possible working fluids.

\subsection{Heat source}

In this work, a biogas CHP by the manufacturer MWM with a maximum electrical power output of $800 \mathrm{~kW}$ provided exhaust gas waste heat at a high temperature level $\left(468-519^{\circ} \mathrm{C}\right)$ and a low temperature heat source at about $90^{\circ} \mathrm{C}$ from the engine coolant. Since the CHP was adapted to the fluctuating energy demand, a typical load condition was an electrical power output of $600 \mathrm{~kW}$. The heat loads for this nominal operating point were given by the CHP manufacturer with $335 \mathrm{~kW}$ for the coolant and $378 \mathrm{~kW}$ for the exhaust gas [20], assuming its cooling to $120^{\circ} \mathrm{C}$ and thus avoiding the condensation of acidic components that could cause corrosion in heat exchangers or exhaust gas lines [21]. Further technical details about the ICE are listed in the supplementary material. A preceding work of our group [22] investigated the composition of the present exhaust gas, i.e. $10.8 \%$ carbon dioxide $\left(\mathrm{CO}_{2}\right), 11.2 \%$ water $\left(\mathrm{H}_{2} \mathrm{O}\right), 7.7 \%$ oxygen $\left(\mathrm{O}_{2}\right)$ and $70.3 \%$ nitrogen $\left(\mathrm{N}_{2}\right)$, and described the determination of its thermodynamic properties. An ethylene glycol + water mixture with a volumetric ratio of 1:1.5 was applied as an engine coolant. Its thermodynamic properties were available from the supplier [23]. In the present scenario, the exhaust gas waste heat was exploited completely by the CORC plant, while up to $145 \mathrm{~kW}$ of the coolant heat load was required for district heating. 


\subsection{Cycle architecture}

Fig. 1 presents the process flow diagram of the CORC plant, showing the exhaust gas line and the main circuits, namely the high temperature (HT) and low temperature (LT) organic Rankine cycles, the intermediate cycle (IC) and the engine coolant cycle (CC). The thermodynamic process was analogous in both ORC and is described exemplarily for the HT-ORC, employing the state points shown in Fig. 1. The liquid working fluid was pressurized by the HT feed pump (7-1) and preheated in a recuperator (1-2). A further heating, evaporation and superheating was conducted in a direct evaporator (2-3), exploiting heat from the exhaust gas (B-C). A turbine was employed as an expander (4-5) and drove a generator. Subsequently, the vapor was cooled down in the recuperator (5-6), after which it was further cooled and liquified in the HT condenser (6-7), where the heat was transferred to the IC (G-H). Additional waste heat from a further cooling of the exhaust gas $(\mathrm{F}-\mathrm{G})$ and from the CHP engine coolant (E-F) was added to the IC in the heat exchangers $\mathrm{HE} 1$ and $\mathrm{HE} \mathrm{2,} \mathrm{respectively.} \mathrm{The} \mathrm{heat} \mathrm{load} \mathrm{of} \mathrm{the}$ IC was then employed to drive the LT-ORC and its condensation heat was discharged to the ambient air.

Within the exhaust gas line, a fan was used to take off a part of the cooled exhaust gas after HE 1 and mix it with the hot exhaust gas in front of the direct evaporator. Thus, the mass flow rate was increased, which led to a better heat transfer, while a lower temperature of the exhaust gas decreased the risk of thermal decomposition of the working fluid in the direct evaporator. Another fan after HE 1 was used to compensate exhaust gas pressure losses caused by the heat exchangers that may interfere with the operation of the CHP. The application of the IC, where an ethylene glycol + water mixture was employed as a heat carrier fluid, allowed for a higher degree of independence between the two working cycles and thus to an improved operational behavior. Furthermore, the IC enabled for an operation, where the LT-ORC was shut down to provide heat from HE 1 and the HT condenser to the district heating infrastructure via HE 2. On the other hand, the IC led to exergy losses and a decrease in the electrical power output because of the IC pump.

\subsection{Thermodynamic cycle model}

For the evaluation of cycle architectures and the selection of working fluids, the CORC plant was modeled by employing the first and second law of thermodynamics, assuming that the plant is in steady state. The isentropic 


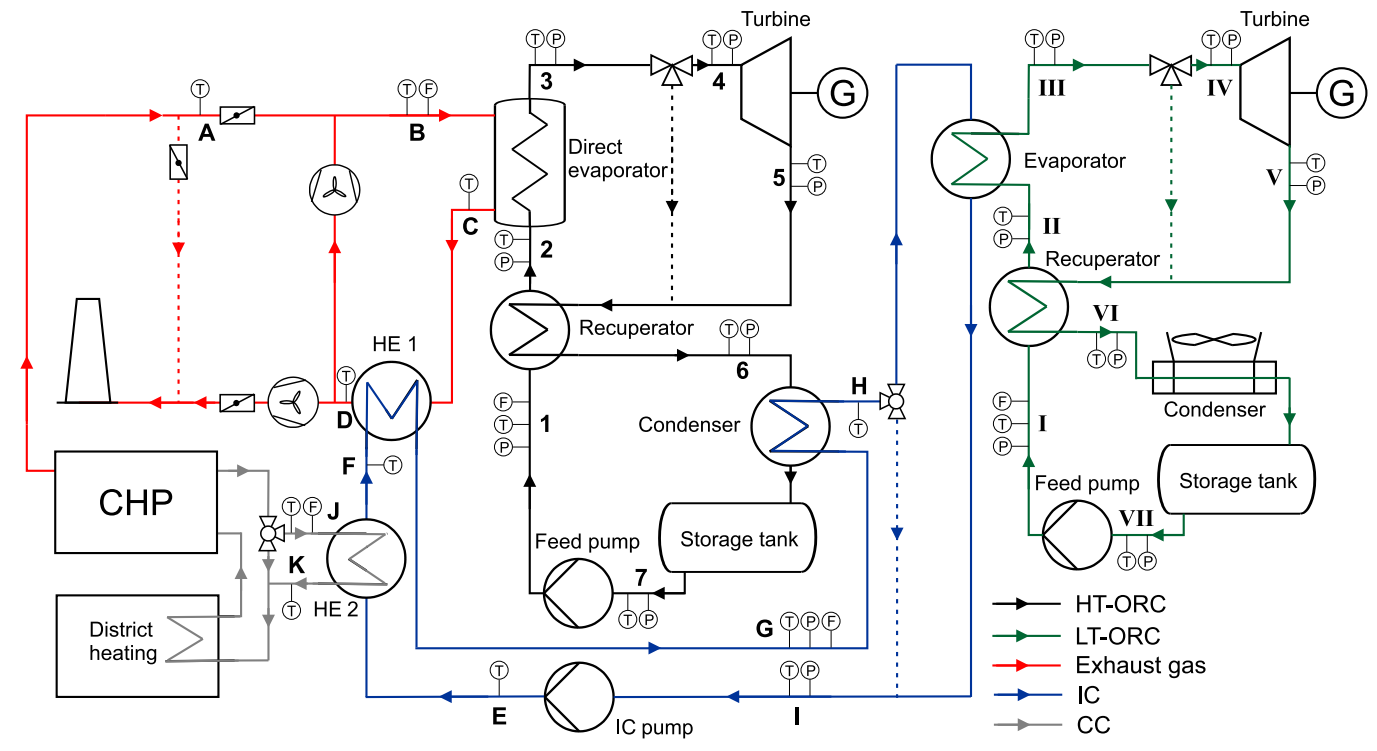

Figure 1: Process flow diagram of the cascaded ORC plant.

efficiencies of the HT turbine and the LT turbine were 72 and $78 \%$ [24, 25], respectively, while the isentropic efficiency of the feed pumps was specified to be 30\%, based on the findings of Quoilin et al. [6]. Furthermore, the temperature profile within the heat exchangers and especially the temperature difference between the fluids was of key importance for the cycle design, where it is known that a relatively large temperature difference is required for the exhaust gas heat exchangers because of low heat transfer coefficient values [26]. Thus, the pinch point temperature difference (PPTD) of the direct evaporator was estimated to be $32 \mathrm{~K}$. For the heat transfer between fluids in vapor and liquid state, plate heat exchangers were employed with minimum temperature difference values between 2 and $5 \mathrm{~K}$. The minimum condensation temperature of the LT-ORC was set to $35^{\circ} \mathrm{C}$ in order to guarantee a suitable temperature difference to the ambient air. From preceding works of our group [19, 22], it was known that heat losses for the direct evaporator and HE 1 were not negligible so that a heat loss factor was introduced here. A heat loss was also considered for the piping between the direct evaporator and the turbine inlet with a temperature decrease of $2 \mathrm{~K}$. Furthermore, the pressure losses were estimated on the basis of further experimental data and the VDI Wärmeatlas [27], which was especially important for the HT working fluid within the direct evaporator and the subsequent piping up to the 
turbine.

The heat flow transferred from the exhaust gas to the HT working fluid was

$$
\dot{Q}_{2,3}=\dot{m}_{\mathrm{HT}} \cdot\left(h_{3}-h_{2}\right)=-\dot{m}_{\mathrm{Exh}} \cdot \bar{c}_{\mathrm{p}, \mathrm{Exh}} \cdot\left(T_{\mathrm{C}}-T_{\mathrm{B}}\right) \cdot L_{\mathrm{DE}},
$$

with the mass flow rates $\dot{m}_{\mathrm{HT}}$ and $\dot{m}_{\mathrm{Exh}}$ of the HT working fluid and the exhaust gas, the working fluids' specific enthalpies $h_{2}$ and $h_{3}$ at the inlet and outlet of the evaporator, the exhaust gas mean isobaric heat capacity $\bar{c}_{\mathrm{p}, \text { Exh }}$ and its inlet and outlet temperatures $T_{\mathrm{B}}$ and $T_{\mathrm{C}}$, respectively. The factor $L_{\mathrm{DE}}$ was employed to consider a heat loss from the exhaust gas to the environment and was assumed to be 0.94 in the present scenario.

The HT turbine output power was

$$
P_{\mathrm{HT}-\mathrm{T}}=P_{4,5}=\dot{m}_{\mathrm{HT}} \cdot\left(h_{5}-h_{4}\right),
$$

with

$$
h_{5}=h_{4}+\left(h_{5 s}-h_{4}\right) \cdot \eta_{s, \mathrm{HT}-\mathrm{T}},
$$

where $h_{5 s}$ was the specific enthalpy at pressure $p_{5}$ and entropy $s_{4}$, while $\eta_{s, \mathrm{HT}-\mathrm{T}}$ was the isentropic efficiency of the HT turbine.

Following Shu et al. [13], the regenerative rate of the recuperator was

$$
\frac{T_{5}-T_{6}}{T_{5}-T_{1}} \leq 0.8
$$

and the heat flow within the recuperator

$$
\dot{Q}_{1,2}=\dot{m}_{\mathrm{HT}} \cdot\left(h_{2}-h_{1}\right)=-\dot{m}_{\mathrm{HT}} \cdot\left(h_{6}-h_{5}\right) .
$$

The heat transferred from the HT working fluid to the ethylene glycol + water mixture in the condenser was

$$
\dot{Q}_{6,7}=\dot{m}_{\mathrm{HT}} \cdot\left(h_{7}-h_{6}\right)=-\dot{m}_{\mathrm{IC}} \cdot \bar{c}_{\mathrm{p}, \mathrm{IC}} \cdot\left(T_{\mathrm{H}}-T_{\mathrm{G}}\right),
$$

where a heat loss was neglected because of the compact size of that plate heat exchanger.

The power consumption of the HT feed pump was

$$
P_{\mathrm{HT}-\mathrm{P}}=P_{7,1}=\dot{m}_{\mathrm{HT}} \cdot\left(h_{1}-h_{7}\right),
$$


with

$$
h_{1}=h_{7}+\frac{h_{1 s}-h_{7}}{\eta_{s, \mathrm{HT}-\mathrm{P}}}
$$

where $h_{1 s}$ was the specific enthalpy at pressure $p_{1}$ and entropy $s_{7}$, while $\eta_{s, \mathrm{HT}-\mathrm{P}}$ was the isentropic efficiency of the pump.

Additional heat was added to the IC by HE 1

$$
\dot{Q}_{\mathrm{F}, \mathrm{G}}=\dot{m}_{\mathrm{IC}} \cdot \bar{c}_{\mathrm{p}, \mathrm{IC}} \cdot\left(T_{\mathrm{G}}-T_{\mathrm{F}}\right)=-\dot{m}_{\mathrm{Exh}} \cdot \bar{c}_{\mathrm{p}, \mathrm{Exh}} \cdot\left(T_{\mathrm{D}}-T_{\mathrm{C}}\right) \cdot L_{\mathrm{HE} 1},
$$

where a factor $L_{\mathrm{HE1}}=0.98$ was assumed to consider a heat loss to the environment.

The engine coolant heat transferred to the IC via HE 2 was

$$
\dot{Q}_{\mathrm{E}, \mathrm{F}}=\dot{m}_{\mathrm{IC}} \cdot \bar{c}_{\mathrm{p}, \mathrm{IC}} \cdot\left(T_{\mathrm{F}}-T_{\mathrm{E}}\right)=-\dot{m}_{\mathrm{CC}} \cdot \bar{c}_{\mathrm{p}, \mathrm{CC}} \cdot\left(T_{\mathrm{K}}-T_{\mathrm{J}}\right) .
$$

The LT-ORC was driven by the heat that was transferred from the IC via the LT evaporator

$$
\dot{Q}_{\mathrm{II}, \mathrm{III}}=\dot{m}_{\mathrm{LT}} \cdot\left(h_{\mathrm{III}}-h_{\mathrm{II}}\right)=-\dot{m}_{\mathrm{IC}} \cdot \bar{c}_{\mathrm{p}, \mathrm{IC}} \cdot\left(T_{\mathrm{I}}-T_{\mathrm{H}}\right),
$$

while the working circuit was modeled in the same way as the HT-ORC. However, it should be noted that the heat from the LT condenser was transferred to the ambient air

$$
\dot{Q}_{\mathrm{VII}, \mathrm{VI}}=\dot{m}_{\mathrm{LT}} \cdot\left(h_{\mathrm{VII}}-h_{\mathrm{VI}}\right)=-\dot{m}_{\mathrm{Air}} \cdot \bar{c}_{\mathrm{p}, \mathrm{Air}} \cdot\left(T_{\mathrm{Air}, \text { out }}-T_{\mathrm{Air}, \text { in }}\right) .
$$

Subsequently, the performance of the HT-ORC was evaluated by employing the thermal efficiency

$$
\eta_{\mathrm{th}, \mathrm{HT}}=\frac{\left|P_{\mathrm{HT}-\mathrm{T}}+P_{\mathrm{HT}-\mathrm{P}}\right|}{\dot{Q}_{2,3}},
$$

that describes the net power output $P_{\text {net,HT }}$ in relation to the heat input from the heat source. The thermal efficiency of the LT-ORC was calculated analogously, while that of the overall plant was

$$
\eta_{\mathrm{th}, \mathrm{tot}}=\frac{P_{\mathrm{net}, \mathrm{HT}}+P_{\mathrm{net}, \mathrm{LT}}}{\dot{Q}_{B, D}+\dot{Q}_{J, K}} .
$$

Furthermore, an exergy analysis was carried out to estimate the irreversibilities that occur in all components of the CORC system. The exergy flow at a state point $i$ was

$$
\dot{E}_{i}=\dot{m} \cdot\left(\left(h_{i}-h_{0}\right)-T_{0} \cdot\left(s_{i}-s_{0}\right)\right)
$$


where the subscript 0 represents ambient conditions and $T_{0}$ was assumed to be $298.15 \mathrm{~K}$.

For a thermodynamic process $i-j$ in system A, the exergy change was

$$
\Delta \dot{E}_{i, j}^{\mathrm{A}}=\dot{E}_{j}^{\mathrm{A}}-\dot{E}_{i}^{\mathrm{A}}
$$

and is always associated with exergy loss, which was calculated by

$$
\dot{I}_{A, B}=\Delta \dot{E}_{i, j}^{\mathrm{B}}-\Delta \dot{E}_{i, j}^{\mathrm{A}},
$$

for an energy transfer from system A to system B. For a thermodynamic process without energy transfer, e.g. an isenthalpic process, the exergy loss is equivalent to the exergy change.

The total exergy input to the CORC was

$$
\dot{E}_{\mathrm{in}, \text { tot }}=\Delta \dot{E}_{\mathrm{A}, \text { out }}^{\mathrm{Exh}}+\Delta \dot{E}_{\mathrm{J}, \mathrm{K}}^{\mathrm{CC}}+\Delta \dot{E}_{7,1}^{\mathrm{HT}}+\Delta \dot{E}_{\mathrm{VII}, \mathrm{I}}^{\mathrm{LT}}
$$

and the exergy efficiency was

$$
\eta_{\mathrm{e}, \mathrm{tot}}=\frac{P_{\mathrm{net}, \mathrm{HT}}+P_{\mathrm{net}, \mathrm{LT}}}{\dot{E}_{\mathrm{in}, \mathrm{tot}}} .
$$

\subsection{Working fluid selection}

The selection of an appropriate working fluid is of central importance for the ORC design and has been discussed in numerous publications. However, for the present CORC, a working fluid pair had to be found both for the HTORC and the LT-ORC, respectively, which had to match with each other as well as with the heat sources and the heat sink, leading to the maximization of performance in terms of thermal efficiency and output power. Furthermore, environmental aspects, such as the ozone depletion potential (ODP) and the global warming potential (GWP), safety factors, like toxicity and flammability [28], as well as practical and legal restrictions had to be taken into account. Regarding the latter aspects, important criteria were a condensation pressure nearby ambient pressure to avoid air leakage into the system [29] and a maximum pressure of 20 bar to obtain technical approval and to allow for the use of standard industrial components. Moreover, the working fluids' normal boiling point temperature (NBPT) should be above $25^{\circ} \mathrm{C}$, which allowed to open the circuits and conduct constructional modifications of the experimental setup without removing the working fluids. 


\subsubsection{HT-ORC working fluid}

For the recovery of high temperature waste heat, Lai et al. [30] found that alkanes, aromates, hydrocarbones and linear siloxanes are promising candidates for the application in ORC. Different case studies were modeled and calculated in Ref. [30], using the BACKONE and PC-SAFT equations of state (EOS) for determining thermodynamic properties. Regarding the present work, the case of interest was an ORC with an internal heat exchanger (recuperator), a maximum cycle temperature (turbine inlet) of $250^{\circ} \mathrm{C}$ and a minimum (condensation) temperature of $85^{\circ} \mathrm{C}$. Among the investigated fluids, toluene and hexamethyldisiloxane (MM) complied with the present pressure requirements and led to thermal efficiencies of 22.6 and $20.9 \%$, respectively.

Branchini et al. [31] presented a numerical study for different ORC configurations, including a comparison between working fluids. A calculation tool was developed on the basis of thermodynamic properties from FluidProp. For a high temperature application with a heat source temperature of $400^{\circ} \mathrm{C}$, it showed that aromatic hydrocarbons had the highest potential and in this group toluene was particularly recommended.

Another fluid selection approach was published by Rödder et al. [32] for a case study that was very close to the boundary conditions of the present work. A $520 \mathrm{kWe}$ biogas CHP represented the heat source and the turbine inlet temperature was $280^{\circ} \mathrm{C}$. The fluid ranking by Rödder et al. [32] took 22 criteria into account, being thermodynamic properties, procedural parameters, environmental, safety and economic issues. Their performance analysis was done with the simulation software EBSILON ${ }^{\circledR}$ Professional using REFPROP for the thermodynamic properties. Again, toluene turned out to be the most suitable substance for the high temperature cycle.

These findings were in line with a recent review by Shi et al. [10], where it was found that various other research groups consider toluene as a superior working fluid for HT-ORC. However, a comparison between toluene and MM was carried out in this work. Table 1 lists basic fluid properties, where the thermodynamic data were calculated with REFPROP 9.1 [33], based on highly accurate EOS by Lemmon et al. [34] and Colonna et al. [35]. Both fluids are highly flammable and hazardous to health and aquatic life so that a detailed consideration of safety aspects had to be carried out. The autoignition temperature of toluene and $\mathrm{MM}$ are $535^{\circ} \mathrm{C}[36]$ and $340^{\circ} \mathrm{C}[37]$, respectively, while the maximum temperature of the exhaust gas was $519^{\circ} \mathrm{C}$. 
Thus, the fire hazard for MM was considerably higher than that for toluene. Another important criterion was the thermal stability of the working fluids. Andersen et al. [38] studied the thermal stability of toluene at a temperature of $315^{\circ} \mathrm{C}$ and obtained a decomposition rate of 3.3 years for the loss of $50 \%$ of the pure fluid. On the basis of these data, the maximum operational temperature for toluene was assumed to be $300^{\circ} \mathrm{C}$ in the present work. For MM, Preißinger et al. [39] determined a decomposition rate of less than $3.5 \%$ per year at a temperature of $300^{\circ} \mathrm{C}$ and recommended it as a maximum operational temperature. Beneficial characteristics of toluene are its zero ozone depletion and global warming potentials [40], while no such data were available for MM.

Subsequently, the performance of the HT-ORC was calculated for both working fluids. The design points are depicted in Fig. 2 by means of a temperature-entropy diagram, while Table 2 lists the most important thermodynamic properties. Further details on the results and boundary conditions are given in the supplementary material. For toluene, a subcritical ORC was determined to be optimal, with a heat input of $264 \mathrm{~kW}$, a turbine output power of $44 \mathrm{~kW}$ and a power consumption of $4 \mathrm{~kW}$ for the feed pump so that the thermal efficiency was $15.2 \%$. The mass flow rate of toluene was $0.56 \mathrm{~kg} / \mathrm{s}$ so that the heat flow transferred to the IC within the condenser was $222 \mathrm{~kW}$. Furthermore, the temperature profiles of the exhaust gas and the IC fluid are illustrated in Fig. 2, where it can be seen for the evaporator that the pinch point occurred at a saturated liquid state and at a saturated vapor state for the condenser. For this cycle design, the exhaust gas recirculation system allowed for an increase of the exhaust gas mass flow rate to an value of $1.3 \mathrm{~kg} / \mathrm{s}$ and a correlated decrease of the exhaust gas temperature from 492 to $382^{\circ} \mathrm{C}$ at the evaporator inlet, which lowered the risk of thermal decomposition of the working fluid at hot spots.

A supercritical ORC design was found to be optimal for MM as a working fluid, where the mass flow rate was $0.98 \mathrm{~kg} / \mathrm{s}$, and led to a heat input of $268 \mathrm{~kW}$, a turbine output power of $41 \mathrm{~kW}$ and a power consumption of $9 \mathrm{~kW}$ for the feed pump so that a thermal efficiency of $11.9 \%$ was determined. While the temperature profile within the condenser was similar to the case with toluene, the pinch point within the evaporator was at the exhaust gas outlet and the working fluid inlet so that an exhaust gas recirculation system could not be applied, which led to the assumption of a lower working fluid operational time and a higher fire hazard. Based on these findings, toluene was selected as a working fluid for the present HT-ORC because of its higher 
thermal efficiency and power output, but also due to beneficial operational and safety aspects.

Table 1: Properties of toluene and hexamethyldisiloxane, considered as working fluids for the HT-ORC.

\begin{tabular}{lll} 
& Toluene & $\mathrm{MM}$ \\
\hline Chemical formula & $\mathrm{C}_{7} \mathrm{H}_{8}$ & $\mathrm{C}_{6} \mathrm{H}_{18} \mathrm{OSi}_{2}$ \\
CAS number & $108-88-3$ & $107-46-0$ \\
Molecular weight & $92.138 \mathrm{~g} / \mathrm{mol}$ & $162.38 \mathrm{~g} / \mathrm{mol}$ \\
Critical temperature & $318.60^{\circ} \mathrm{C}$ & $245.6^{\circ} \mathrm{C}$ \\
Critical pressure & $41.263 \mathrm{bar}$ & $19.39 \mathrm{bar}$ \\
Normal boiling point & $110.60^{\circ} \mathrm{C}$ & $100.25^{\circ} \mathrm{C}$ \\
Thermal stability & $300^{\circ} \mathrm{C}$ & $300^{\circ} \mathrm{C}$ \\
Autoignition temperature & $535^{\circ} \mathrm{C}$ & $340^{\circ} \mathrm{C}$ \\
ODP & 0 & $n / a$ \\
GWP & 0 & $n / a$ \\
\hline
\end{tabular}

Table 2: Design points of the HT-ORC with toluene and hexamethyldisiloxane as a working fluid.

\begin{tabular}{|c|c|c|c|c|c|c|c|c|}
\hline \multirow{3}{*}{$\begin{array}{c}\text { Design } \\
\text { point }\end{array}$} & \multicolumn{4}{|c|}{ Toluene } & \multicolumn{4}{|c|}{ MM } \\
\hline & $T$ & $p$ & $h$ & $s$ & $T$ & $p$ & $h$ & $s$ \\
\hline & ${ }^{\circ} \mathrm{C}$ & bar & $\mathrm{kJ} / \mathrm{kg}$ & $\mathrm{kJ} /(\mathrm{kg} \mathrm{K})$ & ${ }^{\circ} \mathrm{C}$ & bar & $\mathrm{kJ} / \mathrm{kg}$ & $\mathrm{kJ} /(\mathrm{kg} \mathrm{K})$ \\
\hline 1 & 102.0 & 17.80 & -15.97 & -0.048 & 103.8 & 20.00 & 8.54 & 0.015 \\
\hline 2 & 155.0 & 17.78 & 93.57 & 0.225 & 181.3 & 19.80 & 180.52 & 0.430 \\
\hline 3 & 255.0 & 17.10 & 564.53 & 1.168 & 262.0 & 19.50 & 454.96 & 0.978 \\
\hline 4 & 253.0 & 16.72 & 561.46 & 1.163 & 260.0 & 18.90 & 452.31 & 0.974 \\
\hline 5 & 185.9 & 1.01 & 482.55 & 1.229 & 216.4 & 1.34 & 410.10 & 1.008 \\
\hline 6 & 118.7 & 1.01 & 372.94 & 0.972 & 126.3 & 1.34 & 237.98 & 0.620 \\
\hline 7 & 99.0 & 1.01 & -22.97 & -0.061 & 100.0 & 1.33 & -0.51 & -0.001 \\
\hline
\end{tabular}

\subsubsection{LT-ORC working fluid}

The selection of suitable ORC working fluids to convert low grade heat was investigated by numerous researchers [41, 42, 43], where a focus was on high thermal efficiency and turbine power output, but also on economic, environmental and safety aspects. For heat source temperatures below $120^{\circ} \mathrm{C}$, 

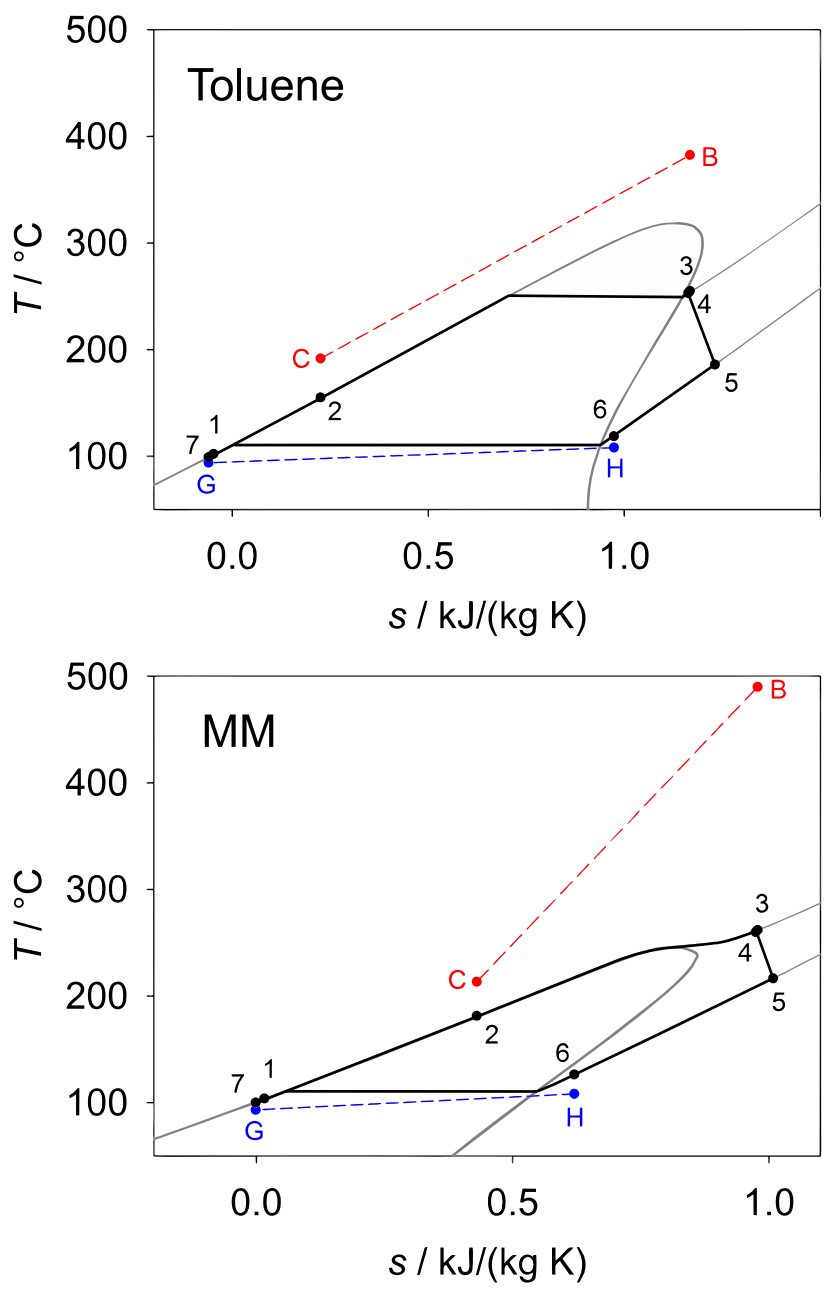

Figure 2: Temperature-entropy diagram of the HT-ORC with toluene (top) and MM (bottom) as a working fluid. 
mainly alkanes and traditional refrigerants were investigated, where the latter often contain fluorine and chlorine so that they have unfavorable ODP and GWP values. Furthermore, refrigerants are known for their relatively high cost [44]. Bao et al. [9] and Quoilin et al. [6] reviewed different working fluid studies, where for evaporation and condensation temperatures of about $90^{\circ} \mathrm{C}$ and $35^{\circ} \mathrm{C}$, respectively, R123, pentane, R152a, R600 and R290 were recommended. Furthermore, Desideri et al. [29] found that Solkatherm SES36 and R245fa were promising working fluids for a low temperature ORC.

Another aspect that was considered in the present work was the requirement of a working fluid with a normal boiling point higher than $25^{\circ} \mathrm{C}$ to allow constructional changes of the plant without removing the fluid and also avoided the loss of fluid while the ORC was shut down. Furthermore, refrigerants that contain chlorine were not considered as possible working fluids due to their ozone depletion potential.

Thus, most of the common working fluids for low temperature applications were ruled out and pentane, 2-methylbutane, dodecafluoropentane, diethyl ether, RE245fa2, RE347mcc and SES36 were considered in the present work. Important basic properties of these fluids are listed in Table 3, where it has to be noted that SES36 is an azeotropic mixture of R365mfc and the perfluoropolyether Galden HT-55 so that a chemical formula and a CAS number are not given here. Furthermore, it can be seen that the GWP for pentane, 2-methylbutane and diethyl ether are relatively low with values between 4 and 20, while those of the fluorinated fluids are distinctly higher with values between 530 and 8550 . All of the fluids were suitable in terms of safety because of reasonable toxicity and autoignition temperatures that were higher than the heat source temperature. Subsequently, the performance of the working fluids in a subcritical LT-ORC was determined with the cycle model, where the thermodynamic properties were obtained from REFPROP 9.1, based on accurate EOS [34, 45, 46, 47, 48, 49], except for SES36, where the properties were given by the supplier Solvay [50].

The heat source condition was known from the calculation of the HTORC and additional heat from HE 1 and HE 2 with an overall heat flow of $505 \mathrm{~kW}$, while the condensation temperature was set to $35^{\circ} \mathrm{C}$, which led to a suitable temperature difference to the ambient air. The determined evaporation and condensation pressures, mass flow rates, turbine output power, feed pump power consumption and thermal efficiencies are listed in Table 4, while detailed data on the boundary conditions and the resulting cycle conditions are presented in the supplementary material. 
It was found that the working fluid SES36 leads to the highest turbine output power with $48 \mathrm{~kW}$ as well as the highest thermal efficiency of $8.9 \%$. The temperature-entropy diagram of this LT-ORC configuration is depicted in Fig. 3, including the temperature profiles of the IC and the ambient air. The next highest thermal efficiency of $8.2 \%$ was reached by diethyl ether and RE245fa2, while dodecafluoropentane yielded the lowest value with $7.7 \%$. Based on these findings, SES36 was selected as a working fluid for the present LT-ORC. However, it should be noted that at a later point in time a preliminary EOS for SES36 became available in REFPROP that led to considerably poorer cycle results with a thermal efficiency of only $7.2 \%$. This decrease in cycle performance was mainly a consequence of a higher enthalpy of evaporation that was obtained by the preliminary EOS. Obviously, a clarification of the thermodynamic properties of SES36 is crucial for future studies. 


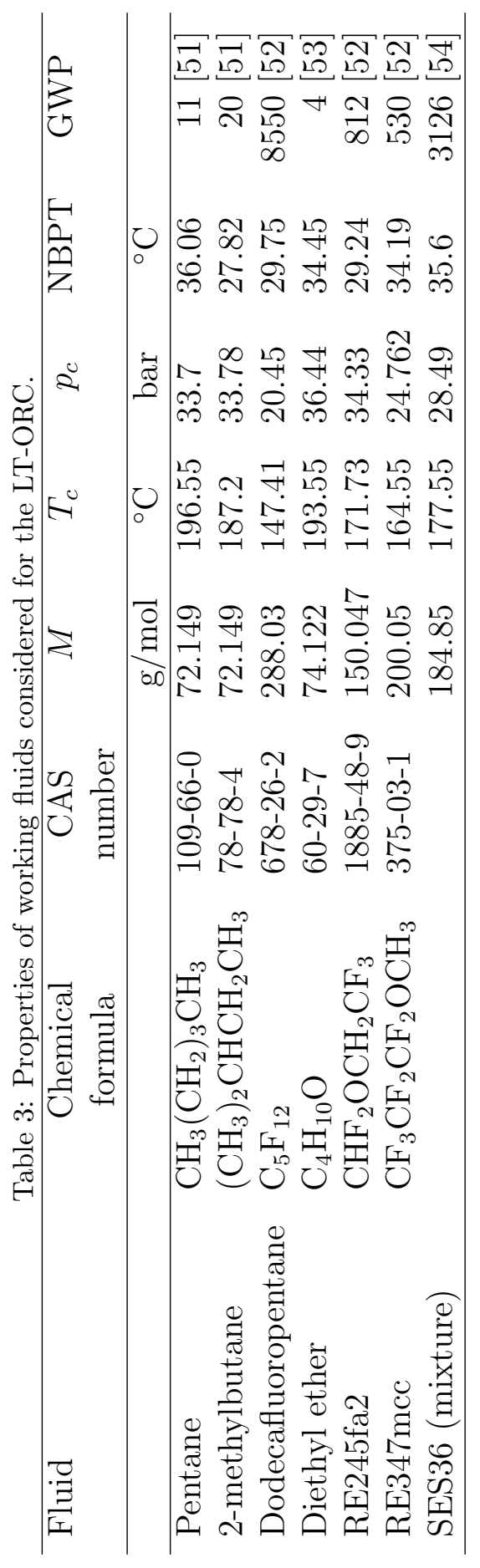


Table 4: Design results of the LT-ORC and different working fluids.

\begin{tabular}{lllllll}
\hline Fluid & $p_{\text {evap }}$ & $p_{\text {cond }}$ & $\dot{m}_{\mathrm{LT}}$ & $P_{\mathrm{LT}-\mathrm{T}}$ & $P_{\mathrm{LT}-\mathrm{P}}$ & $\eta_{\text {th,LT }}$ \\
\hline & $\mathrm{bar}$ & $\mathrm{bar}$ & $\mathrm{kg} / \mathrm{s}$ & $\mathrm{kW}$ & $\mathrm{kW}$ & \\
\hline Pentane & 3.35 & 1.00 & 1.24 & 42.89 & 1.57 & 0.0817 \\
2-methylbutane & 4.19 & 1.31 & 1.31 & 43.44 & 2.08 & 0.0818 \\
Dodecafluoropentane & 4.34 & 1.25 & 4.70 & 41.93 & 3.04 & 0.0769 \\
Diethyl ether & 3.66 & 1.05 & 1.24 & 43.14 & 1.54 & 0.0823 \\
RE245fa2 & 4.56 & 1.27 & 2.46 & 43.55 & 1.95 & 0.0823 \\
RE347mcc & 3.79 & 1.06 & 3.26 & 42.61 & 2.13 & 0.0800 \\
SES36 & 3.50 & 1.01 & 3.34 & 48.09 & 2.93 & 0.0893 \\
\hline
\end{tabular}

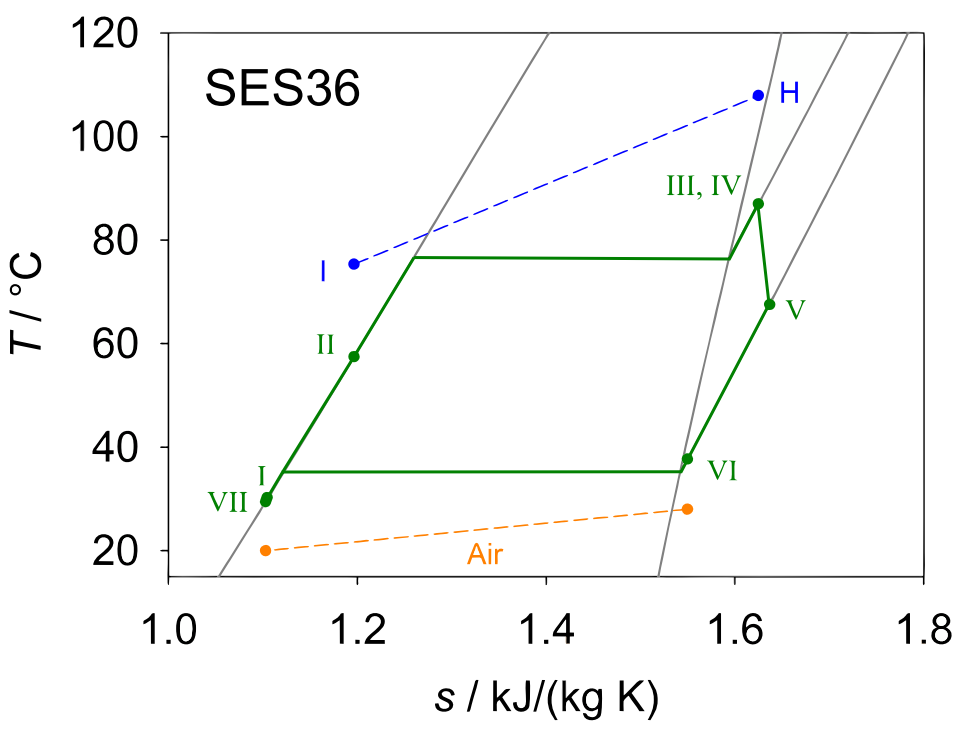

Figure 3: Temperature-entropy diagram of the LT-ORC with SES36 as a working fluid, employing thermodynamic properties given by Solvay.

\subsection{Design performance}

The calculated total mechanical power output of the CORC plant was $85 \mathrm{~kW}$ for a heat input of $568 \mathrm{~kW}$ so that the total thermal efficiency of the CORC was $15.0 \%$, cf. Eq. (14). However, the employed cycle model strongly simplified the CORC plant and the effective output power was reduced by several ancillary plant components, such as generators, voltage transformer units and control instrumentation. Despite this fact, the presented efficiency 
values allow for a comparison with the literature, in which commonly an analysis of simplified thermodynamic cycles without the consideration of ancillary components is carried out as well. Thus, a recent study of CORC systems for the WHR of a diesel engine by Shu et al. [15] stated a maximum thermal efficiency of $11.7 \%$ so that the present design seems to be suitable.

Moreover, an exergy analysis was carried out for the obtained CORC design that allowed for the evaluation of irreversibilities in each plant component. The exergy flow and exergy losses are depicted in a Sankey diagram in Fig. 4, where it can be seen that the majority of exergy input was provided through the exhaust gas with $177.4 \mathrm{~kW}$, while only $31.8 \mathrm{~kW}$ was transferred through the engine cooling cycle. Large exergy losses were caused by the exhaust gas recirculation system $(19.2 \mathrm{~kW})$, the direct evaporator $(20.7 \mathrm{~kW})$ and HE $1(12.9 \mathrm{~kW})$ due to the large decrease in temperature level. Thus, an exergy flow of $106.4 \mathrm{~kW}$ was transferred to the HT-ORC in the direct evaporator, while $18.2 \mathrm{~kW}$ were provided to the IC in HE 1. By considering the feed pump and the recuperator, an exergy flow of $122.9 \mathrm{~kW}$ was supplied to the HT turbine. For the expansion process, the exergy loss was $11.4 \mathrm{~kW}$, while the generated mechanical work was $44.2 \mathrm{~kW}$. Because of the relatively high condensation temperature, an exergy flow of $49 \mathrm{~kW}$ was discharged in the HT condenser.

The exergy from the engine coolant was transferred in HE 2, where the exergy destruction was low with $1.7 \mathrm{~kW}$ due to the small temperature difference in the plate heat exchanger. In total, the IC provided an exergy flow of $93.2 \mathrm{~kW}$ to the LT evaporator, where a loss of $13.4 \mathrm{~kW}$ was determined. An exergy flow of $86.2 \mathrm{~kW}$ was provided to the turbine that caused an exergy destruction of $14.1 \mathrm{~kW}$ and generated a mechanical power of $48.1 \mathrm{~kW}$, while an exergy flow of $15.8 \mathrm{~kW}$ was discharged to the ambient air in the LT condenser.

Summarizing, the total exergy input to the CORC plant was $209 \mathrm{~kW}$ and with an overall mechanical power output of $85 \mathrm{~kW}$ an exergy efficiency of $40.6 \%$ was determined for the present ORC architecture, which is in good agreement with an exergy efficiency of $38.7 \%$ that was determined for a CORC system by Shu et al. [15].

\section{Description of the test rig}

The CORC plant was built in two 20 feet sea containers that were placed on top of each other, except for the exhaust gas heat exchangers and the 


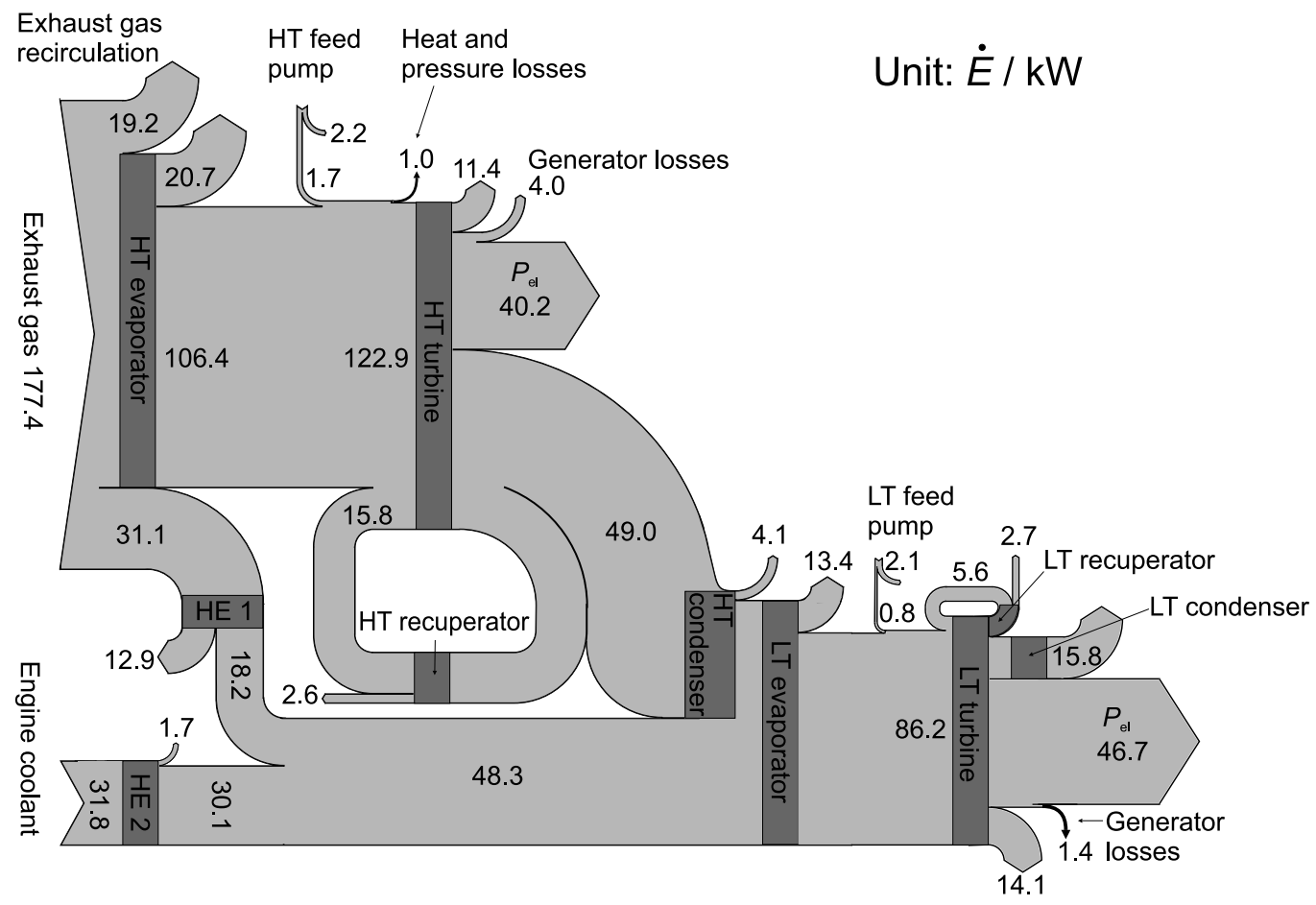

Figure 4: Exergy flow and exergy losses of the present CORC design. 
LT condenser, which were located outside of and next to the containers. The modular design with four modules enabled for a convenient preparatory work at the factory and ensured the transportability to the CHP, where the separate modules were connected with each other and with the heat source. Fig. 5 shows a photograph of the completed CORC setup and Fig. 6 presents a technical drawing with a view into the containers. The majority of the HTORC appliances were located in the upper container, except for the HT feed pump to rise the pressure head at the suction support and avoid cavitation. The LT-ORC was set up in the bottoming container and the IC was employed to carry heat from HE 1, HE 2 and the HT condenser to the LT evaporators.

The plant was built in accordance with the Pressure Equipment Directive (PED) 2014/68/EU of the European Union and was approved and certified by Technischer Überwachungsverein (TÜV), a German notified body, in terms of safety and explosion prevention. The piping system was made of stainless steel (Material No. 1.4571) to avoid corrosion, which was especially important for the heat exchangers that were in contact with exhaust gas [55]. The flanges of the piping system were sealed with graphite gaskets with a stainless steel reinforcement, other auxiliary equipment and instrumentation was sealed by gaskets made of copper or polytetrafluoroethylene (PTFE). These materials provided a high thermal and chemical stability and led to a low rate of leakage, proven by pressure tests. The CORC test rig was widely built from standard industrial parts. Plate heat exchangers from GEA GmbH model WP10L-300 were applied as HT recuperator and HT condenser, two parallel WP10L-300 as the LT recuperator, while the LT evaporator was realized with a WP10L-150 and WP10L-300, connected in series. Here, a vapor-liquid flow distributor was assembled within the inlet of the second plate heat exchanger to supply each channel with the same vapor quality and thus to avoid an insufficient heat transfer performance. Furthermore, a model WP7MU-120 was used as HE 2, which was located in the CHP housing. The design and test of a multi-coil helical direct evaporator for the HT-ORC was presented in a preceding work of our group [22] and the exhaust gas heat exchanger HE 1, depicted in Fig. 7, was also in-house designed and of cross-flow type with tubes, finned on the exhaust gas side. For the LT-ORC, an air cooled condenser of the V type by LU-VE Contardo model SHVDN 966 was employed.

Multi stage centrifugal pumps by Grundfos models CRNE3-23 and CRNE10-03 were used as feed pumps for the HT-ORC and the LT-ORC, respectively, while a model 3D 32-200, supplied by EBARA, was chosen as 
IC pump. These pumps were connected to frequency inverters to adjust the mass flow rates.

Single stage radial inflow turbines were employed as expanders in both ORC and were provided by an associated group. In these turbines, the rotor was directly connected to the generator shaft without using a gearbox, thus avoiding mechanical losses and resulting in a compact size, simple design and low maintenance requirements. Furthermore, hydrodynamic shaft bearings lubricated by the working fluid were used, which enabled for a hermetical and oil free construction. Thus, no oil could find its way into the working fluid, which prevented decomposition.

Looking at the turbine of the HT-ORC, shown in Fig. 8, the expansion pressure ratio was high with a value of 16.9 and correlated with a high enthalpy drop that led to a highly supersonic flow of the toluene vapor passing the laval nozzles, which were located circularly around the rotor and formed the turbine stator. The majority of the working fluid's enthalpy drop took place in the stator so that the rotor was of low reaction type and converted the kinetic energy of the vapor flow into mechanical work. The large enthalpy drop within one stage, together with a low mass flow rate, resulted in a high rotational speed of $600 \mathrm{~Hz}$ at the nominal operation point. The axial deflection of the steam in the direction of the turbine outlet was realized with a smooth cone behind the rotor blades. The LT turbine was of the same type, however, the expansion pressure ratio and the enthalpy drop were lower so that the SES36 flow was only slightly supersonic and with a higher mass flow rate, the maximum rotational speed was $120 \mathrm{~Hz}$. The HT rotor was made of titanium and thus provided a high mechanical resilience, while all other parts of the turbines were made of stainless steel. Furthermore, the stator and rotor of these turbines were easy to assemble so that modified geometries could be tested.

The generators were of brushless synchronous type and could also be operated as a motor to bring the turbines to nominal rotational speed. They worked with an inverter voltage of $416 \mathrm{~V}$ and had an efficiency of $\eta_{\mathrm{G}}=98 \%$, given by the supplier ATE Antriebstechnik und Entwicklungs GmbH. The generated electricity was inverted to a $400 \mathrm{~V}$ alternating current by a feed-in unit SD2R from Sieb \& Meyer and subsequently fed into the public grid. The efficiency of the feed-in unit was given as $\eta_{\mathrm{I}} \geq 95 \%$. The losses for the two hydrodynamic shaft bearings, lubricated with working fluid, were given by the supplier Main-Metall Tribologie $\mathrm{GmbH}$ with 3.2 and $0.4 \mathrm{~kW}$ at the design points of the HT-ORC and the LT-ORC, respectively. The achieved 
generator power $P_{\mathrm{G}}$ was precisely measured by the feed-in unit and with the known efficiency $\eta_{\mathrm{G}}$ and the bearing losses $P_{\mathrm{B}, \mathrm{L}}$, a reliable turbine shaft power could be calculated by

$$
P_{\mathrm{T}}=\frac{P_{\mathrm{G}}}{\eta_{\mathrm{G}}}+P_{\mathrm{B}, \mathrm{L}}
$$

that allowed for a comparison with the results from the cycle design.

The generators and feed-in units were cooled by a separate cooling cycle, using an ethylene glycol + water mixture that was driven by a circulator pump and the heat was released to the ambient air with a dry cooler. Furthermore, the cooling cycle was employed to cool down the working fluid that was taken off after the storage tanks and supplied to the hydrodynamic shaft bearings of the generators. The flow of lubrication fluid was also driven by circulator pumps and fed back to the storage tank after the generator bearings.

Looking at the LT-ORC, a noteworthy component was a steam trap after the recuperator that allowed to discharge working fluid, which was already liquified, directly to the storage tank.

In order to reduce heat losses, all relevant components of the plant as well as the piping system were insulated with rock wool with a thickness of at least $50 \mathrm{~mm}$. The exhaust gas line with the direct evaporator and HE 1 were additionally encased with a sheet metal housing.

\subsection{Control, instrumentation and safety}

For operation and data acquisition, a controller system M1 by Bachmann was used for each ORC, which included a programmable logic controller (PLC), interfaces for digital and analog in- and outputs, as well as a network and fieldbus connection. The software architecture was based on $\mathrm{C}$ programs, which processed the measured data, actuated the devices and controlled a regular plant status. When predefined limits were exceeded, the CORC plant was shut down by the PLC. A web based graphical user interface (GUI) was developed to handle and supervise the operation. This arrangement enabled the plant to run fully automated and unstaffed. The measuring instrumentation is illustrated in Fig. 1 and allowed for the validation of all relevant components.

Temperatures were measured with platinum resistance thermometers with a basic resistance of $1000 \Omega$ (Pt1000), the pressure measurement was conducted with absolute pressure transmitters (APT) S-20 supplied by WIKA. 


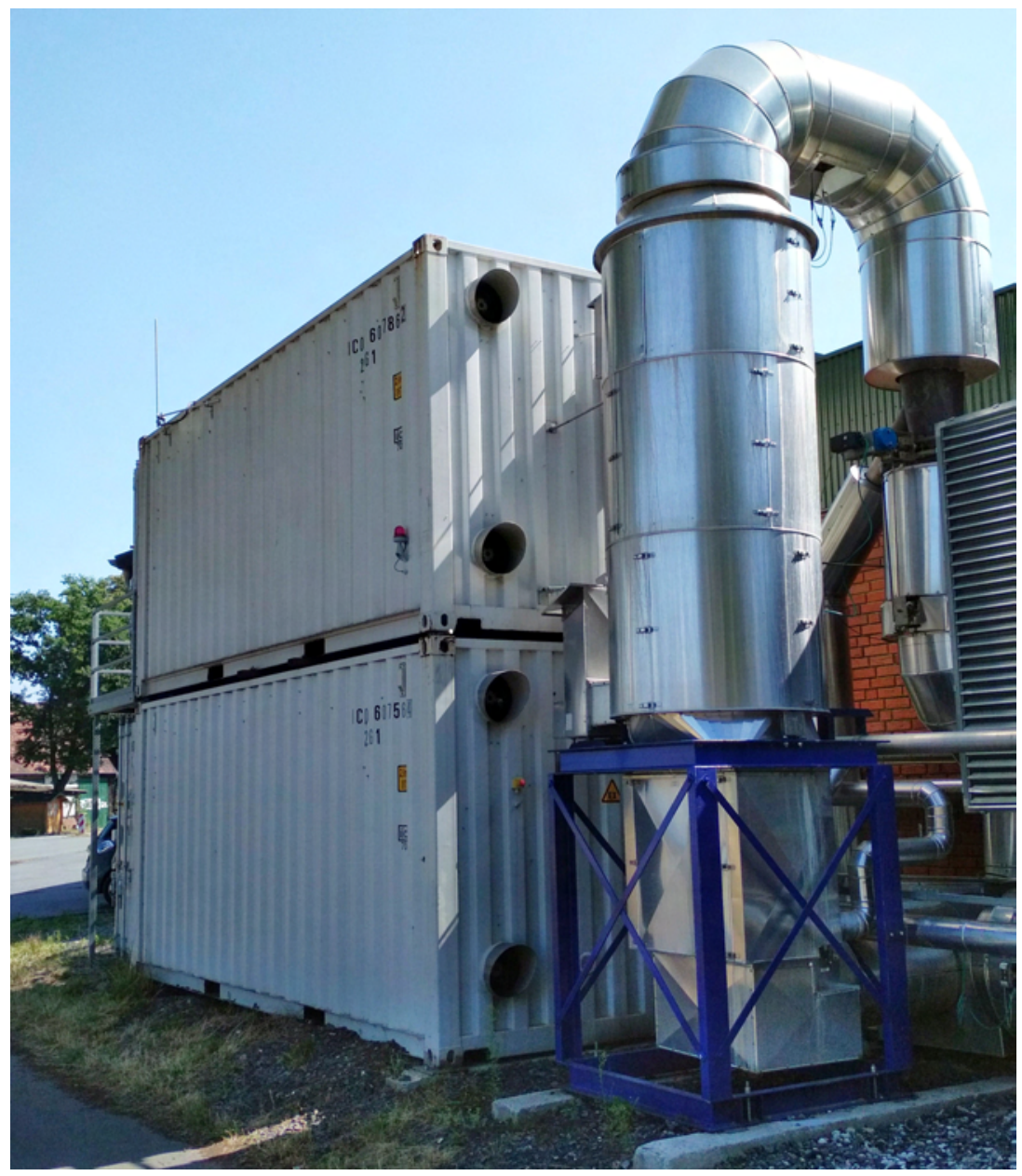

Figure 5: CORC plant in modular design with the direct evaporator and HE 1 in the front, connected to the setup in the containers. 


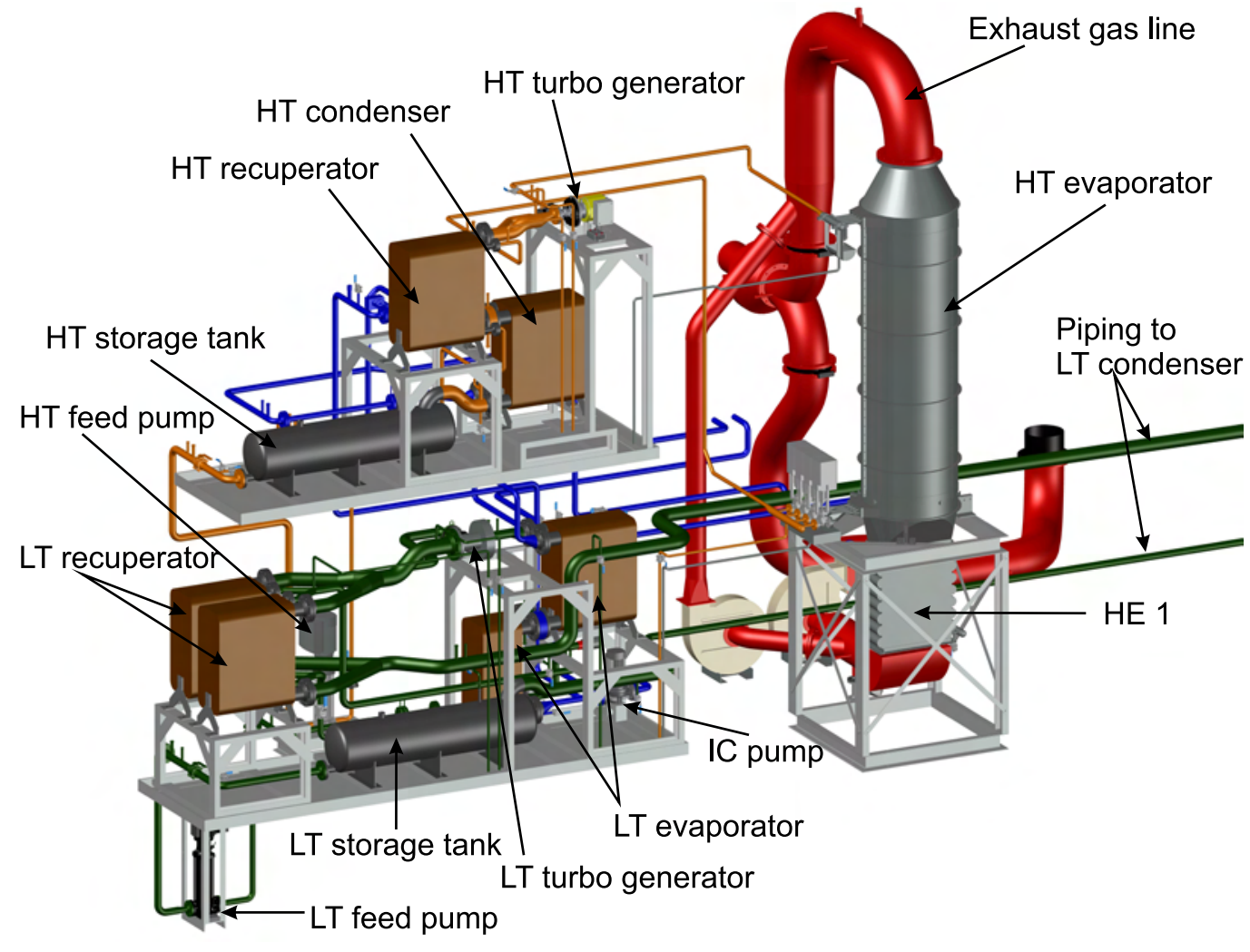

Figure 6: Technical drawing of the CORC rig.

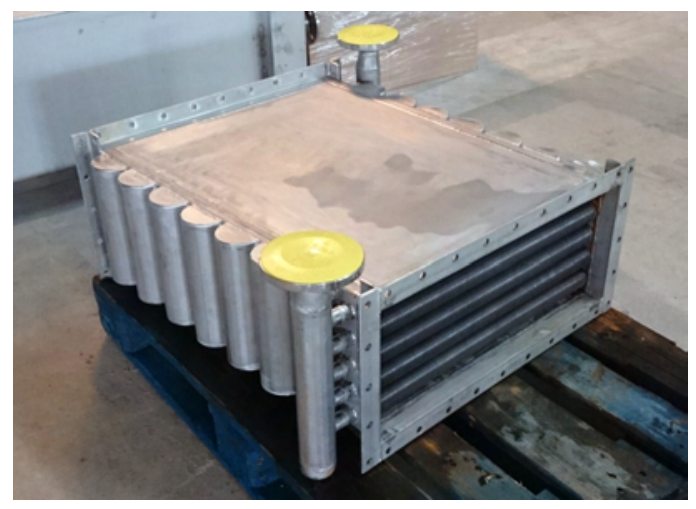

Figure 7: Heat exchanger HE 1 with a view on the finned tubes in the exhaust gas flow passage and flanges for the connection to the IC. 


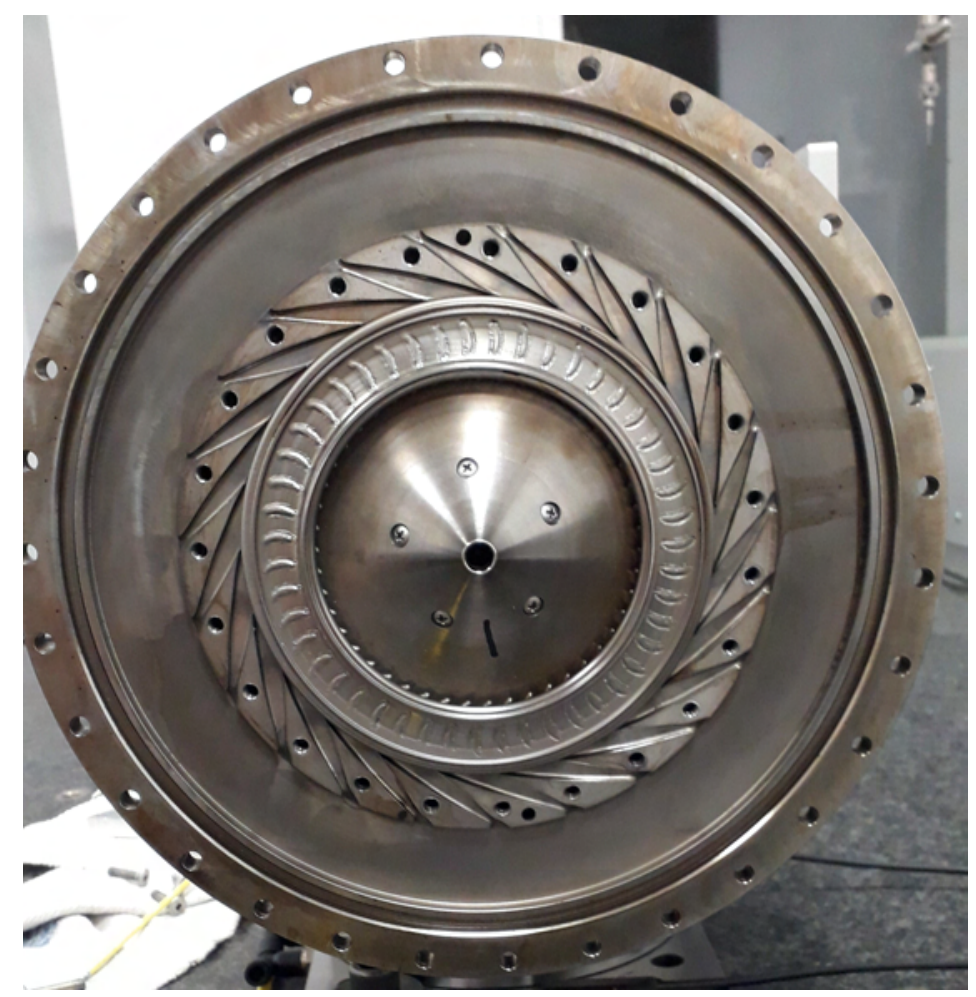

Figure 8: Photograph of the opened HT turbine with a view on the stator, rotor and exit cone. 
For the determination of the mass flow rate in both ORC and the IC, differential pressure flow meters according to DIN EN ISO 5167 were used, equipped with differential pressure transmitters DE 70 by Fischer. A pitot tube static anemometer combined with a C 310 transmitter by KIMO was used for the exhaust gas flow measurement, while the volume flow in the CC was measured with a bypass rotameter supplied by Taconova. Furthermore, the electrical power consumption and the generated power was measured by wattmeters DHZ+ by the supplier NZR. The sensors' measuring ranges and their uncertainties are listed in Table 5. For safety reasons, the plant was equipped with gas and leakage transmitters supplied by Dräger and Baumer, respectively.

In addition, a hard-wired programmed logic controller was installed to shut down the operation in case of crossing default temperature and pressure limits in the CORC, even if the control of the PLC failed.

Table 5: Uncertainties of the measuring equipment.

\begin{tabular}{llll}
\hline Variable & Sensor type & Range & Uncertainty \\
\hline$T$ (exhaust) & Pt1000 & $0-480^{\circ} \mathrm{C}$ & $\pm 0.10 \%$ \\
$T($ ORC) & Pt1000 & $0-350^{\circ} \mathrm{C}$ & $\pm 0.10 \%$ \\
$T($ IC) & Pt1000 & $0-150^{\circ} \mathrm{C}$ & $\pm 0.10 \%$ \\
$p($ ORC high pressure $)$ & APT & $0-25 \mathrm{bar}$ & $\leq \pm 0.5 \%$ \\
$p($ ORC low pressure) & APT & $0-6 \mathrm{bar}$ & $\leq \pm 0.5 \%$ \\
$p($ IC $)$ & APT & $0-6 \mathrm{bar}$ & $\leq \pm 0.5 \%$ \\
$\dot{m}($ HT-ORC) & difference pressure & $0.22-0.71 \mathrm{~kg} / \mathrm{s}$ & $\pm 1.4 \%$ \\
$\dot{m}($ LT-ORC) & difference pressure & $1.31-3.58 \mathrm{~kg} / \mathrm{s}$ & $\pm 1.4 \%$ \\
$\dot{m}($ IC $)$ & difference pressure & $1.43-4.53 \mathrm{~kg} / \mathrm{s}$ & $\pm 1.4 \%$ \\
$\dot{m}($ exhaust gas $)$ & Pitot static tube & $0-2.2 \mathrm{~kg} / \mathrm{s}$ & $\pm 1.2 \%$ \\
$\dot{V}(\mathrm{CC})$ & rotameter & $60-320 \mathrm{l} / \mathrm{min}$ & $\pm 5 \%$ \\
$P_{\mathrm{el}}$ & wattmeter & & $\leq \pm 2 \%$ \\
\hline
\end{tabular}

\section{Results and discussion}

Subsequent to the manufacturing and safety approval, test runs were carried out to evaluate the CORC performance in comparison to the design results. In a first step, it was aimed to bring the HT-ORC close to the nominal design point. Furthermore, the heat supply to the IC and its discharge to 
the LT evaporator as well as the operational behavior of the LT-ORC were investigated.

\subsection{HT-ORC}

For the test runs, at first, the IC pump was started, followed by the HT feed pump at a low rotational frequency and a low supply of exhaust gas to the direct evaporator. The mass flow rates of toluene and exhaust gas were increased gradually until the working fluid at the evaporator exit was slightly superheated. It has to be noted that the toluene passed the turbine bypass at the start up. Subsequently, the turbine was started and set to a low rotational frequency of $200 \mathrm{~Hz}$, followed by the supply of toluene vapor. While increasing the rotational frequency of the turbo-generator, the power output was raised and reached a maximum, which was the optimal turbine speed for the respective operating point. When this steady state point was reached, the heat supply and the rotational frequency of the feed pump were increased stepwise, which caused an increment of the evaporation pressure and allowed for a higher turbine speed and power output.

The measured state points for a steady operational condition are listed in the supplementary material and were compared with the design parameters in form of a temperature-entropy diagram, shown in Fig. 9. It can be seen that the reached vapor quality in front of the turbine, which is a crucial operational factor, was satisfactory. However, it was found that the condensation pressure was higher than the design value, while the temperature difference between the toluene and the IC fluid was large (cf. Fig. 9) and should have allowed for a lower condensation pressure. This issue was caused by non-condensable gases that remained in the circuit, accumulated within the condenser and storage tank and increased the pressure. Furthermore, the heat transfer performance of the recuperator was higher than the design value so that the liquefaction of toluene already started within this heat exchanger. On the other side, the higher heat transfer rate led to a higher degree of preheating so that the working fluid entered the direct evaporator at a temperature of about $185^{\circ} \mathrm{C}$ instead of $155^{\circ} \mathrm{C}$. The operation of the direct evaporator was not affected by these deviating conditions because of the exhaust gas recirculation system that allowed for the adjustment of the heat source temperature profile. Another deviation from the design was a too high working fluid pressure loss between the feed pump and the turbine inlet with a value of about 2.4 bar. A reason for this was the high fluid velocity within the direct evaporator and the following piping with several redirections. The 
pressure loss was compensated with a higher rotational frequency of the feed pump so that the intended pressure at the turbine inlet was reached.

The electric power output of the generator in dependence of the turbine's rotational frequency is depicted in Fig. 10, where the highest power output of $17.5 \mathrm{~kW}$ was reached at $415 \mathrm{~Hz}$. Unfortunately, higher turbine speed and more power output were not achieved in the course of the present work because of a turbo-generator damage that occurred during the experimental progress. It was found that the fiberglass sleeve, that separated the generator rotor from the stator, was macerated by toluene from the hydrodynamic bearings and got into contact with the rotor so that the glass fiber was pulled out of the sleeve and blocked the rotor, as shown in Fig. 11. The ensuing sudden breakdown also led to a damage of the hydrodynamic bearings and a revision of the whole turbo-generator was required.

Looking at the operational parameters, a heat flow input of $212.4 \mathrm{~kW}$ was recalculated with Eq. (1). Furthermore, the expansion process should have yielded a power output of $29.8 \mathrm{~kW}$ at the turbine shaft (cf. Eq. (2)), while the electric output of the generator was only $17.5 \mathrm{~kW}$, as measured by the feed-in unit. The known power losses from the bearings and the generator were about 1.2 and $0.6 \mathrm{~kW}$, respectively, so that the deviation between the expected and measured power output was too high. Reasons could be the non-adiabatic turbo-generator, higher friction losses due to the beginning generator damage and a working fluid flow that exited the turbine with a high velocity. With a recalculated turbine shaft power of $19.3 \mathrm{~kW}$, its isentropic efficiency was $40.3 \%$.

The HT feed pump had a power consumption of $3.5 \mathrm{~kW}$ and an isentropic efficiency of $32.8 \%$, which was lower than the value of $50.4 \%$ given by the supplier Grundfos, but agreed well with values from the literature [21, 29, 56]. It should be noted that the efficiency values given by the manufacturers are commonly related to pumping water so that the quite different thermophysical properties of organic fluids, such as a higher compressibility, could be a reason for lower pump efficiency values.

The experimental results led to a net mechanical power output of $15.8 \mathrm{~kW}$ and with this to a thermal efficiency of $7.4 \%$ for the HT-ORC (cf. Eq. (13)). Furthermore, an exergy analysis was conducted and is presented with a Sankey diagram in Fig. 12 that allowed for a comparison with the design exergy analysis, cf. Fig. 4. The exergy flow transferred from the exhaust gas was $170.8 \mathrm{~kW}$ and in good agreement with the design value of $177.8 \mathrm{~kW}$. The exergy loss through the exhaust gas recirculation system was lower than 
the design value because of a lower decrease of temperature level during the test. Therefore, the temperature difference between the exhaust gas and the toluene was larger in the direct evaporator and led to a higher exergy loss with a value of $27.9 \mathrm{~kW}$. Since the recuperator had a higher heat transfer performance than expected, also the exergy recovery was better with $26.5 \mathrm{~kW}$ instead of $15.8 \mathrm{~kW}$, while the exergy loss of $1 \mathrm{~kW}$ was lower than the expected $2.6 \mathrm{~kW}$ because of a small temperature difference. An exergy flow of $115.5 \mathrm{~kW}$ was provided to the turbine, which is slightly lower than the expected $122.9 \mathrm{~kW}$. Considering that the turbine was operated at off-design conditions with $415 \mathrm{~Hz}$ instead of $600 \mathrm{~Hz}$, the exergy loss was $22.1 \mathrm{~kW}$ and higher than expected.

Thus, the exergy analysis showed that only $10.2 \%$ of the exhaust gas exergy was converted to electric power within the present test runs. Despite this fact, it was found that the required exergy flow can be provided to the turbine, which is a crucial aspect for the further development of the present CORC plant.

Summarizing, the thermodynamic function of the HT-ORC architecture was proven by the present experiments, where particularly the crucial vapor condition at the turbine inlet was close to the design point. A damage of the generator inhibited to operate the turbine at its nominal design point and maximum rotational frequency so that the achieved power output and thermal efficiency were lower than expected. However, the operational behavior of the plant and the exergy analysis led to the assumption that a power output close to the design value should be possible after a revision of the turbo-generator. Further optimization measures are the improvement of the piping between the direct evaporator and the turbine to decrease the pressure loss, and the connection of the storage tank to the vacuum pump to remove non-condensable gases and consequently decrease the condensation pressure.

\section{2. $L T-O R C$}

Because of the damaged generator in the HT-ORC and the fact that the condensation heat of the HT cycle was required to drive the LT-ORC, a steady state operation was not possible at this early stage of the plant test and the LT turbine was not operated. However, the heat transfer from the IC to the LT-ORC and the operational behavior of the circuit was tested in the 


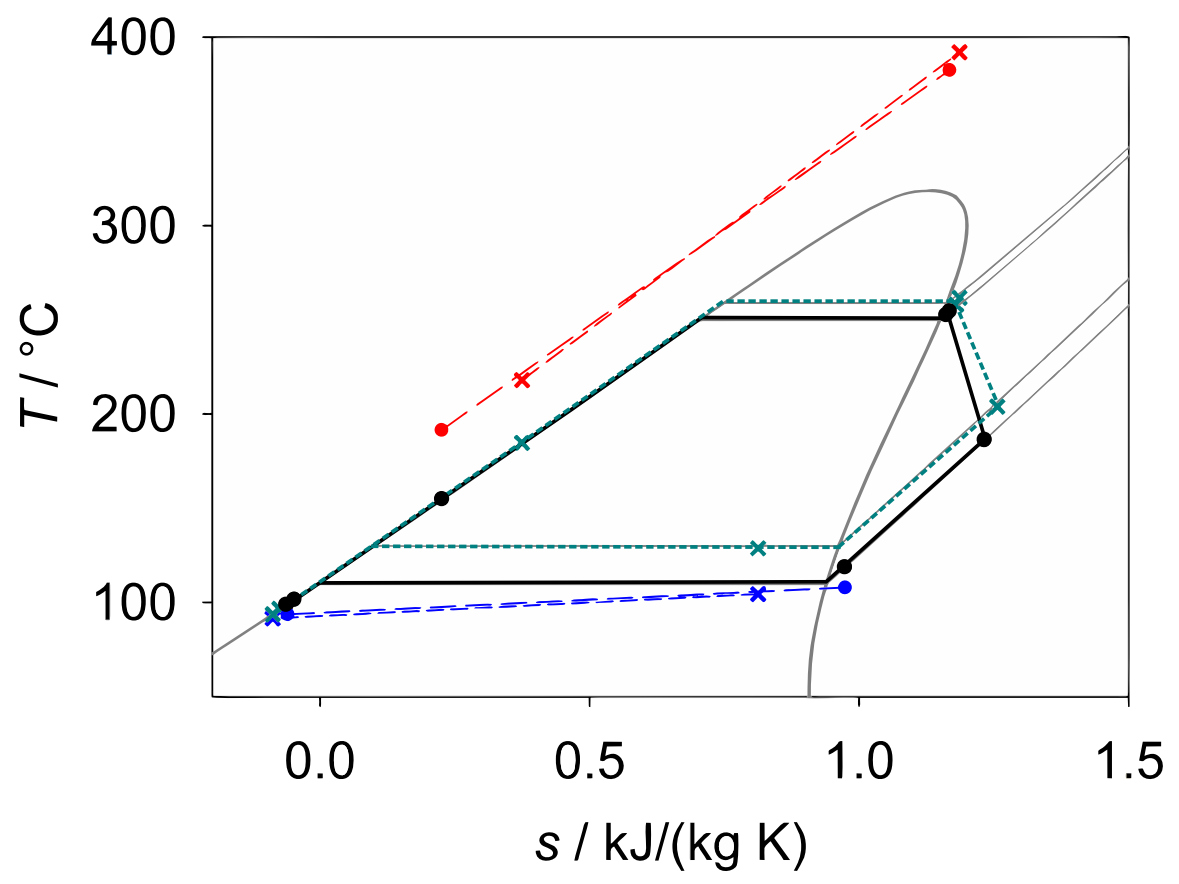

Figure 9: Comparison of design points $(\bullet)$ and experimental results $(\times)$ for the HT-ORC. For identification of the state points, cf. Fig. 2.

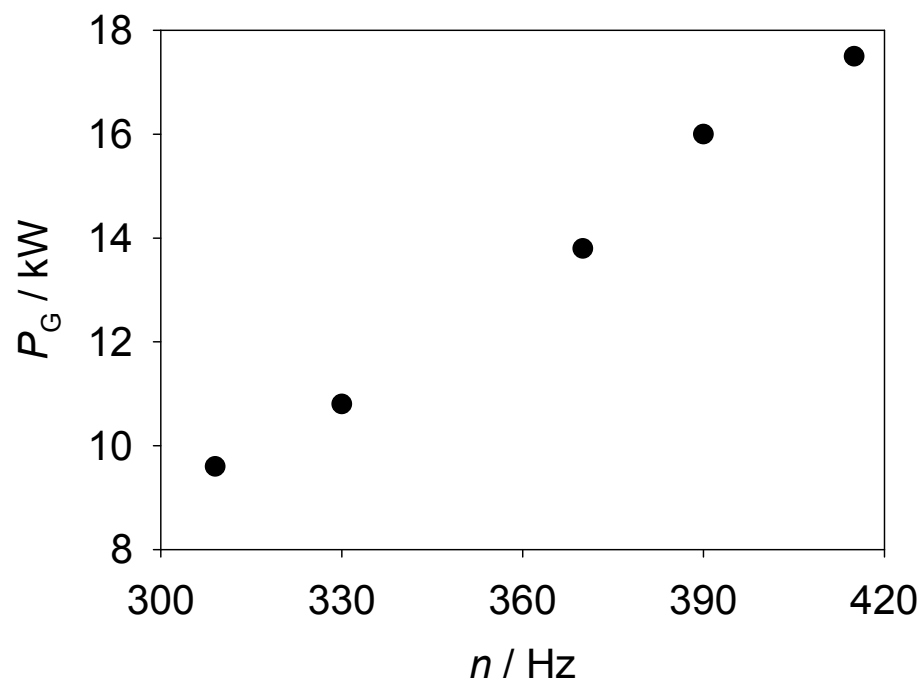

Figure 10: Generator power output as a function of the turbine's rotational frequency. 


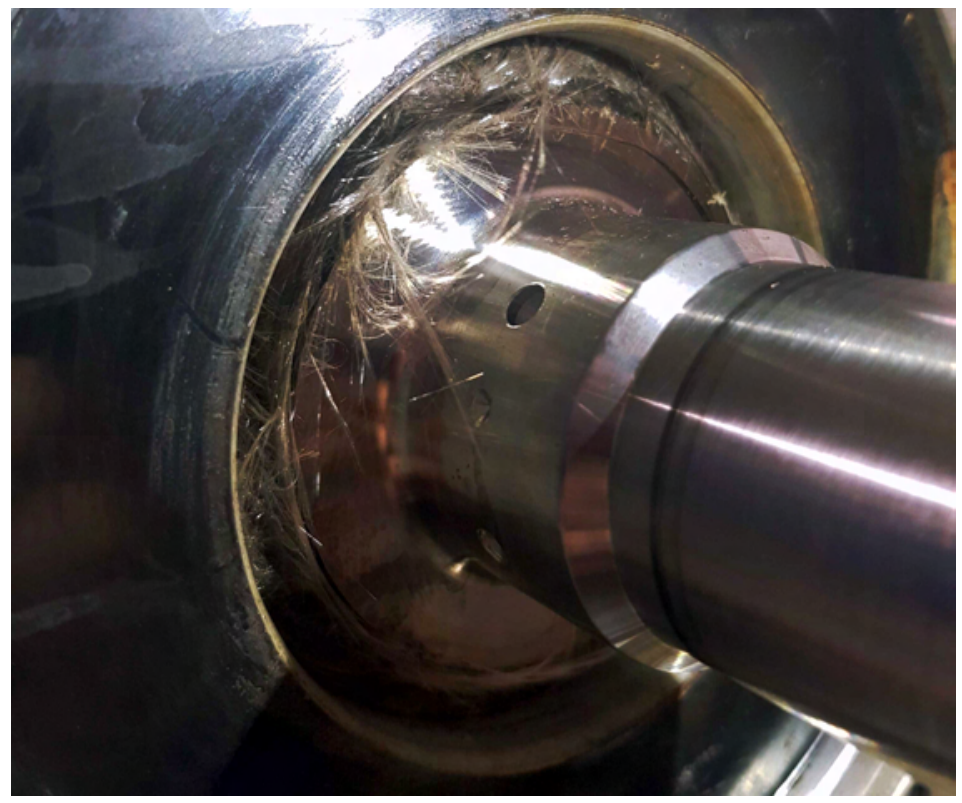

Figure 11: Photograph of the damaged turbo-generator with unwound glass fiber between rotor and stator.

present work. The experimental data were analyzed employing the preliminary EOS for SES36 in REFPROP and the thermodynamic properties from the supplier Solvay. The results are compared by means of pressure-enthalpy diagrams in Fig. 13, where the state points II and VI were recalculated from energy balances (cf. Eqs. (5) and (11)). It can be seen that state point II was in the vapor-liquid region for the thermodynamic properties determined with REFPROP, while this state point was in the liquid state for the properties from Solvay. However, the experimental data, which are listed in the supplementary material, showed a temperature of $87.9^{\circ} \mathrm{C}$ at state point II, which was the boiling temperature for the measured pressure of 4.7 bar so that the evaporation already started within the recuperator. Thus, the thermodynamic properties from the supplier were incorrect regarding the enthalpies and especially the values for the enthalpy of evaporation were too low. It should be noted that the preliminary EOS in REFPROP was not validated in the present work, but seemed to provide a better accuracy.

Furthermore, the experimental results are depicted in a temperatureentropy diagram in Fig. 14 and it was found that the evaporation pressure of 4.7 bar was higher than the design value of 3.5 bar. However, the working 


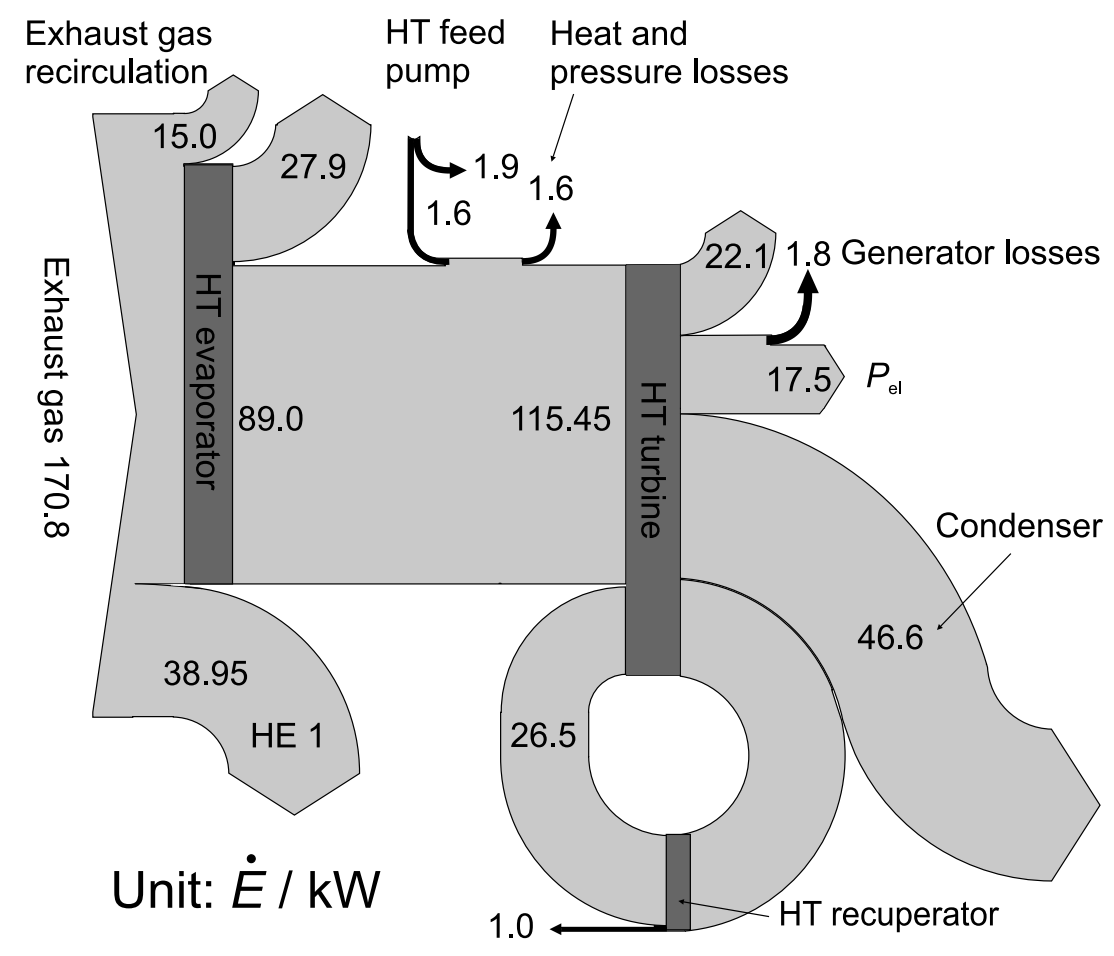

Figure 12: Exergy flow and exergy losses of the HT-ORC test run. 

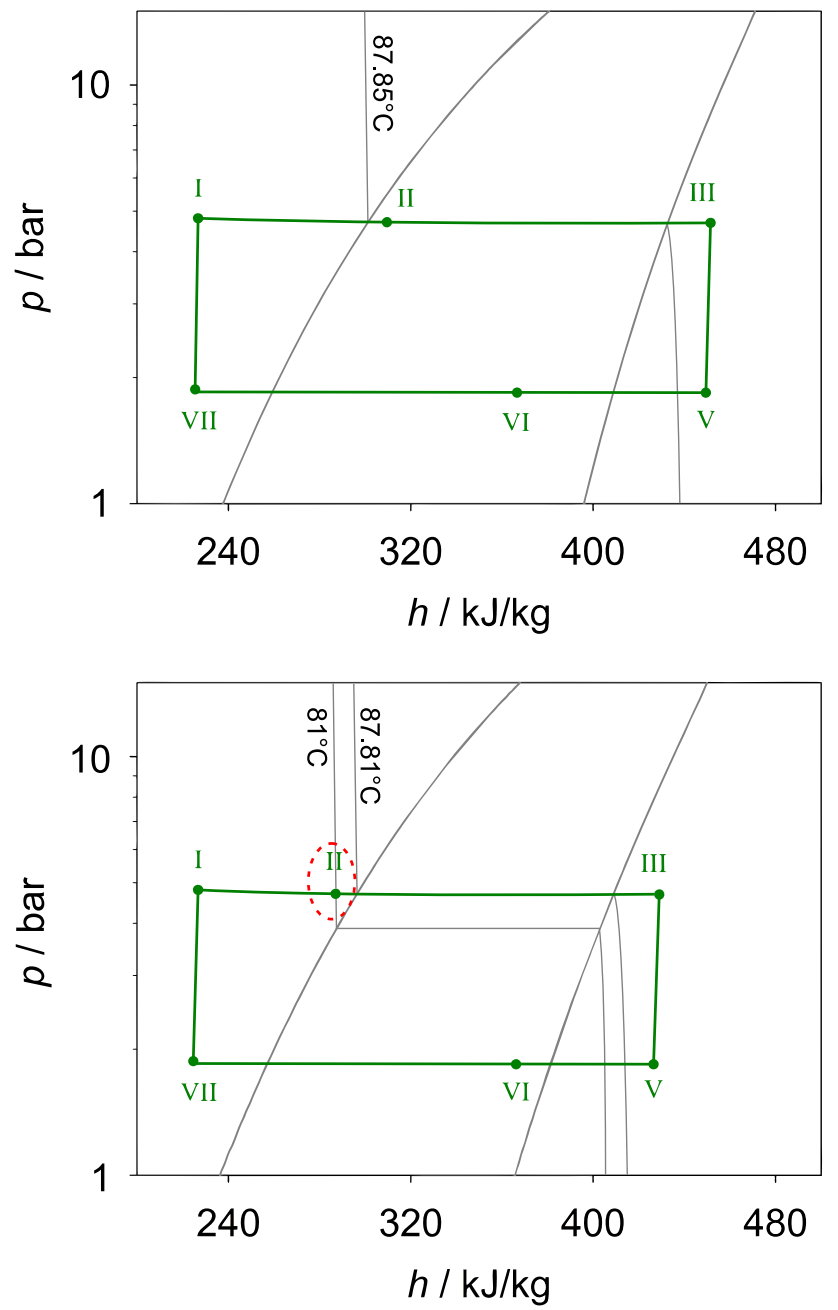

Figure 13: Experimental results of the LT-ORC shown in pressure-enthalpy diagrams, where the thermodynamic properties of SES36 were determined with a preliminary EOS in REFPROP (top) and given by the supplier Solvay (bottom). 
fluid was completely evaporated and the degree of superheating was $18 \mathrm{~K}$. Subsequently, the vapor was expanded with an orifice plate in the turbine bypass so that the enthalpy drop was low with $3 \mathrm{~kW}$, which was caused by heat losses. The heat transfer performance within the recuperator was higher than expected so that a two-phase flow occurred on both sides of the heat exchanger. It was also noted that the condensation pressure was too high with a value of 1.9 bar, caused by non-condensable gases in the condenser and storage tank.

The experiments also showed that the nominal working fluid mass flow rate of $3.34 \mathrm{~kg} / \mathrm{s}$ could not be reached when a state of superheated vapor was attained because the orifice plate that was employed as an expander had a too small aperture. Thus, the maximum mass flow rate of SES36 vapor was $1.5 \mathrm{~kg} / \mathrm{s}$ so that the heat flow to the LT evaporator was $212 \mathrm{~kW}$ and the IC liquid was cooled down to a temperature of $94.1^{\circ} \mathrm{C}$. Subsequently, the remaining heat of the $\mathrm{IC}$ was discharged to the district heating network via HE 2.

Furthermore, the LT feed pump power consumption was $1.9 \mathrm{~kW}$ and had an isentropic efficiency of $16.4 \%$, which was considerably lower than the efficiency of the HT pump. A reason for this was the operation at offdesign conditions with a too low working fluid mass flow rate at the adjusted rotational speed.

An exergy analysis for the LT-ORC operation is illustrated with a Sankey diagram in Fig. 15. An exergy flow was supplied to the IC through the exhaust gas that discharged $36.8 \mathrm{~kW}$ in $\mathrm{HE} 1$, where a loss of $15.4 \mathrm{~kW}$ occurred, as well as through the toluene that transferred $43.8 \mathrm{~kW}$ in the HT condenser, of which $5.5 \mathrm{~kW}$ was lost. Both exergy loss values were higher than expected because of a larger decrease in temperature level. Due to a low working fluid mass flow rate in the LT-ORC, the available exergy was not utilized completely and an exergy flow of $16.6 \mathrm{~kW}$ was discharged to the district heating network in HE 2. However, a low exergy loss of $4.1 \mathrm{~kW}$ was found for the LT evaporator caused by a small temperature difference between the IC fluid and the SES36. The poor pump efficiency led to an exergy destruction of $1.6 \mathrm{~kW}$, while an exergy flow of $0.3 \mathrm{~kW}$ was added to the working fluid. Furthermore, an exergy of $12.9 \mathrm{~kW}$ was transferred to the liquid SES36 in the recuperator, where $2.5 \mathrm{~kW}$ was lost so that this heat exchanger had a better performance than expected. Thus, an exergy flow of $52.2 \mathrm{~kW}$ was provided to the LT expander, which was lower than the expected value of $86.2 \mathrm{~kW}$, but it should be noted that the main reason for this was the too low working fluid 


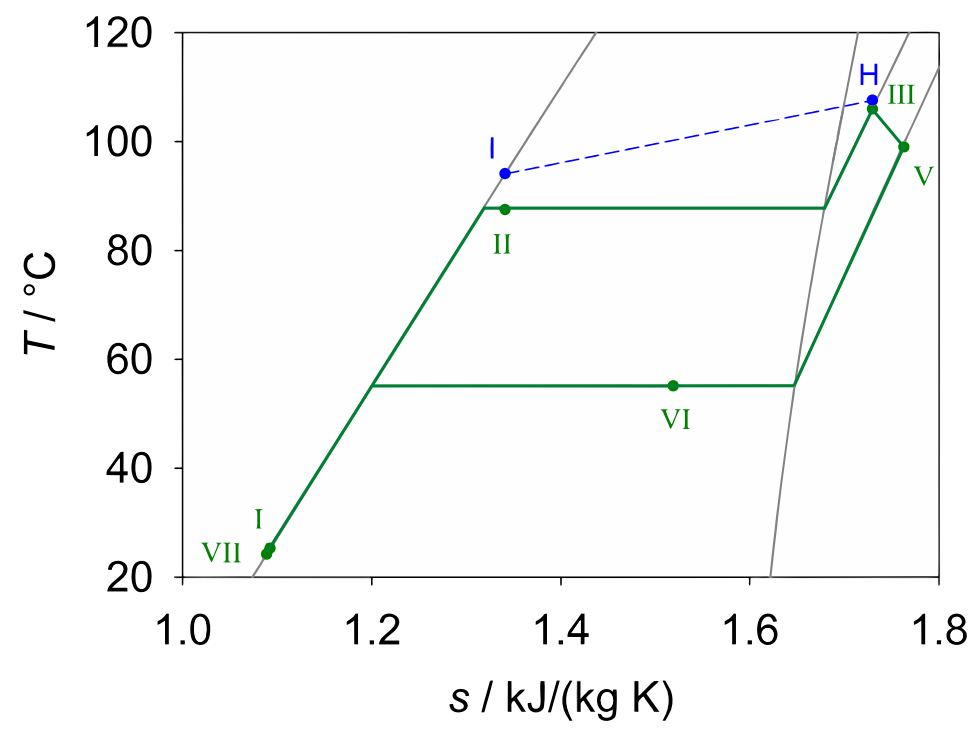

Figure 14: Experimental results of the LT-ORC, employing a preliminary EOS in REFPROP for the determination of SES36 thermodynamic properties.

mass flow rate. Since an orifice plate was used as an expander, no mechanical work was generated and an exergy destruction of $17.5 \mathrm{~kW}$ was noted. As a consequence, the expanded vapor had a high temperature and allowed for a high regenerative rate in the recuperator. Furthermore, the increased condensation pressure and the associated higher condensation temperature led to a larger discharge of exergy to the ambient air in the condenser with a value of $19.3 \mathrm{~kW}$.

Summarizing, the mass flow rate of the IC and its temperature in front of the LT evaporator agreed well with the design parameters so that it can be assumed that the heat supply was suitable. The operation of the LTORC was shown as well, while the available heat and exergy flow could not be utilized completely so that this cycle has to be optimized to reach the expected performance. For this purpose, an orifice plate with a larger aperture or the revised turbo-generator has to be employed to increase the mass flow rate of SES36. Furthermore, a vacuum pump has to be adapted to the storage tank and condenser to remove non-condensable gases that led a too high condensation pressure. 


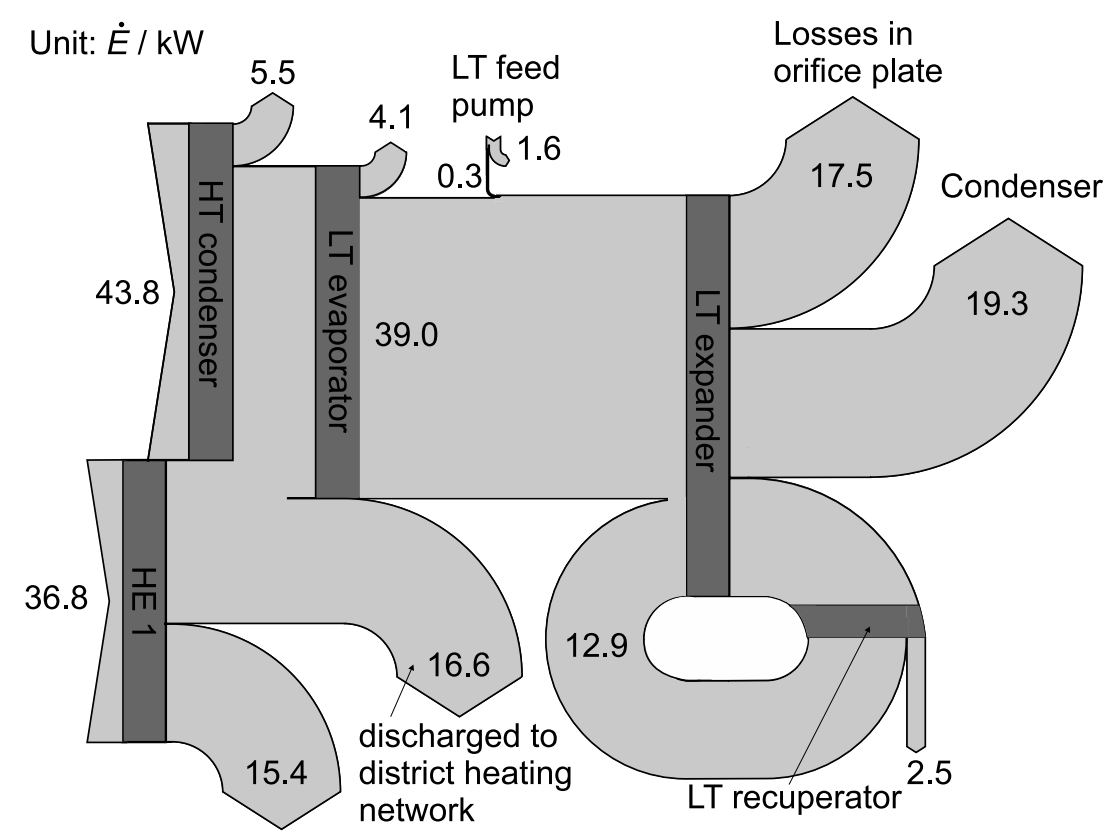

Figure 15: Exergy flow and exergy losses of the LT-ORC test run.

\section{Conclusion}

The present work presents the design and initial operation of two cascaded ORC to exploit waste heat from a biogas CHP, provided at a high and a low temperature level by the exhaust gas and the engine coolant, respectively. The heat sources and boundary limits were analyzed, followed by the determination of a suitable cycle architecture that consisted of the HT-ORC and the LT-ORC, an exhaust gas line with a recirculation system and an intermediate cycle to accumulate the low temperature heat sources and transfer the heat to the LT-ORC. Suitable working fluids were compared and rated by considering not only the cycle efficiency and power output, but also environmental, safety and practical aspects. Toluene was found to be the most suitable working fluid for the HT-ORC with a thermal efficiency of $15.2 \%$, while SES36 was selected as a working fluid for the LT-ORC with a calculated thermal efficiency of $8.9 \%$.

The plant components, which were mainly standard industrial parts, were described, including the instrumentation, safety and control systems as well as data acquisition. Subsequently, results from the initial test runs were presented, where the operational behavior of the HT-ORC was satisfactory and 
also showed a high flexibility with respect to deviating boundary conditions. However, with a maximum generator output of $17.5 \mathrm{~kW}$, the assumed performance was not reached because of a turbo-generator damage that occurred during a further increase of the rotational frequency.

The experiments also showed that the cycle architecture was operational. Low temperature grade heat from different sources was transferred to the IC, from where it was carried and discharged to the LT evaporator. For the LT-ORC, a basic operation with a state of superheated vapor was proven, while the nominal working fluid mass flow rate was not reached because the vapor was not expanded with the turbine at this early stage of experiments, but with an orifice plate that was applied within the turbine bypass. By analyzing the experimental results, it was determined that the thermodynamic properties of SES36, given by the supplier Solvay, were incorrect, which was a reason for the high thermal efficiency obtained from the design calculation. A reliable EOS for SES36 is crucial for further projects that consider this fluid.

Furthermore, it was found that the isentropic efficiencies of the feed pumps were poor with values below $35 \%$, which agreed with the few experimental studies about this issue. In theoretical works, the pump efficiency is often assumed with too high values of about $80 \%$ so that a consideration of the recent experimental results could yield a better accuracy.

In summary, the test runs were promising and demonstrated that the CORC plant was suitable to exploit heat sources at different temperature levels. By accomplishing the optimization measures that were outlined in the present work and a revision of the HT turbo-generator, an adequate performance should be reachable.

\section{Acknowledgements}

This work was supported by the Bundesministerium für Wirtschaft und Energie [Grant No. KF 2363838ST4]. The authors gratefully thank family Willeke, Bergkamen for the appropriation of the test site. Furthermore, we acknowledge Jörn Strumberg and Mathias Knirr for their contributions to the programming and development of control systems.

\section{References}

[1] Global Warming of $1.5^{\circ} \mathrm{C}$. An IPCC Special Report on the impacts of global warming of $1.5^{\circ} \mathrm{C}$ above pre-industrial levels and related global 
greenhouse gas emission pathways, in the context of strengthening the global response to the threat of climate change, sustainable development, and efforts to eradicate poverty, Intergovernmental Panel on Climate Change, Geneva, Switzerland, (2018).

[2] L. Miró, S. Brückner, L. F. Cabeza, Mapping and discussing Industrial Waste Heat (IWH) potentials for different countries, Renewable and Sustainable Energy Reviews 51 (2015) 847-855. https://doi.org/10.1016/j.rser.2015.06.035.

[3] H. Fang, J. Xia, Y. Jiang, Key issues and solutions in a district heating system using low-grade industrial waste heat, Energy 86 (2015) 589-602. https://doi.org/10.1016/j.energy.2015.04.052.

[4] B. Orr, A. Akbarzadeh, M. Mochizuki, R. Singh, A review of car waste heat recovery systems utilising thermoelectric generators and heat pipes, Applied Thermal Engineering 101 (2016) 490-495. https://doi.org/10.1016/j.applthermaleng.2015.10.081.

[5] P. Colonna, E. Casati, C. Trapp, T. Mathijssen, J. Larjola, T. TurunenSaaresti, A. Uusitalo, Organic Rankine Cycle Power Systems: From the Concept to Current Technology, Applications, and an Outlook to the Future, Journal of Engineering for Gas Turbines and Power 137 (2015) 100801. https://doi.org/10.1115/1.4029884.

[6] S. Quoilin, M. Van Den Broek, S. Declaye, P. Dewallef, V. Lemort, Techno-economic survey of Organic Rankine Cycle (ORC) systems, Renewable and Sustainable Energy Reviews 22 (2013) 168-186. https://doi.org/10.1016/j.rser.2013.01.028.

[7] S. Lecompte, H. Huisseune, M. Van Den Broek, B. Vanslambrouck, M. De Paepe, Review of organic Rankine cycle (ORC) architectures for waste heat recovery, Renewable and Sustainable Energy Reviews 47 (2015) 448-461. https://doi.org/10.1016/j.rser.2015.03.089.

[8] B. F. Tchanche, G. Lambrinos, A. Frangoudakis, G. Papadakis, Lowgrade heat conversion into power using organic Rankine cycles-A review of various applications, Renewable and Sustainable Energy Reviews 15 (2011) 3963-3979. https://doi.org/10.1016/j.rser.2011.07.024. 
[9] J. Bao, L. Zhao, A review of working fluid and expander selections for organic Rankine cycle, Renewable and Sustainable Energy Reviews 24 (2013) 325-342. https://doi.org/10.1016/j.rser.2013.03.040.

[10] L. Shi, G. Shu, H. Tian, S. Deng, A review of modified Organic Rankine cycles (ORCs) for internal combustion engine waste heat recovery (ICEWHR), Renewable and Sustainable Energy Reviews 92 (2018) 95-110. https://doi.org/10.1016/j.rser.2018.04.023.

[11] A. Mahmoudi, M. Fazli, M. Morad, A recent review of waste heat recovery by Organic Rankine Cycle, Applied Thermal Engineering 143 (2018) 660-675. https://doi.org/10.1016/j.applthermaleng.2018.07.136.

[12] E. Wang, H. Zhang, Y. Zhao, B. Fan, Y. Wu, Q. Mu, Performance analysis of a novel system combining a dual loop organic Rankine cycle (ORC) with a gasoline engine, Energy 43 (2012) 385-395. https://doi.org/10.1016/j.energy.2012.04.006.

[13] G. Shu, L. Liu, H. Tian, H. Wei, Y. Liang, Analysis of regenerative dual-loop organic Rankine cycles (DORCs) used in engine waste heat recovery, Energy Conversion and Management 76 (2013) 234-243. https://doi.org/10.1016/j.enconman.2013.07.036.

[14] H. Tian, L. Liu, G. Shu, H. Wei, X. Liang, Theoretical research on working fluid selection for a high-temperature regenerative transcritical dualloop engine organic Rankine cycle, Energy Conversion and Management 86 (2014) 764-773. https://doi.org/10.1016/j.enconman.2014.05.081.

[15] G. Shu, G. Yu, H. Tian, H. Wei, X. Liang, Z. Huang, Multiapproach evaluations of a cascade-Organic Rankine Cycle (C-ORC) system driven by diesel engine waste heat: Part A-Thermodynamic evaluations, Energy Conversion and Management 108 (2016) 579-595. https://doi.org/10.1016/j.enconman.2015.10.084.

[16] G. Yu, G. Shu, H. Tian, Y. Huo, W. Zhu, Experimental investigations on a cascaded steam-/organic-Rankine-cycle (RC/ORC) system for waste heat recovery (WHR) from diesel engine, Energy Conversion and Management 129 (2016) 43-51. https://doi.org/10.1016/j.enconman.2016.10.010. 
[17] R. Freymann, W. Strobl, A. Obieglo, Der Turbosteamer: Ein System zur Kraft-Wärme-Kopplung im Automobil, MTZ-Motortechnische Zeitschrift 69 (2008) 404-412. https://doi.org/10.1007/BF03227452.

[18] R. Freymann, J. Ringler, M. Seifert, T. Horst, The second generation turbosteamer, MTZ worldwide 73 (2012) 18-23. https://doi.org/10.1365/s38313-012-0138-1.

[19] F. H. Dubberke, M. Linnemann, W. K. Abbas, E. Baumhögger, K.-P. Priebe, M. Roedder, M. Neef, J. Vrabec, Experimental setup of a cascaded two-stage organic Rankine cycle, Applied Thermal Engineering 131 (2018) 958-964. https://doi.org/10.1016/j.applthermaleng.2017.11.137.

[20] Technical datasheet MWM TCG 2016 V16 C, Caterpillar Energy Solutions GmbH: Mannheim, Germany (2013).

[21] D. Maraver, J. Royo, V. Lemort, S. Quoilin, Systematic optimization of subcritical and transcritical organic Rankine cycles (ORCs) constrained by technical parameters in multiple applications, Applied Energy 117 (2014) 11-29. https://doi.org/10.1016/j.apenergy.2013.11.076.

[22] M. Linnemann, K.-P. Priebe, G. Herres, C. Wolff, J. Vrabec, Design and test of a multi-coil helical evaporator for a high temperature organic Rankine cycle plant driven by biogas waste heat, Energy Conversion and Management 195 (2019) 1402-1414. https://doi.org/10.1016/j.enconman.2019.05.053.

[23] Technical datasheet Glykosol N, pro KÜHLSOLE GmbH: Düren, Germany (2007).

[24] D. Fiaschi, G. Manfrida, F. Maraschiello, Design and performance prediction of radial ORC turboexpanders, Applied Energy 138 (2015) 517532. https://doi.org/10.1016/j.apenergy.2014.10.052.

[25] L. Da Lio, G. Manente, A. Lazzaretto, Predicting the optimum design of single stage axial expanders in ORC systems: Is there a single efficiency map for different working fluids?, Applied Energy 167 (2016) 44-58. https://doi.org/10.1016/j.apenergy.2016.01.020. 
[26] J. P. Gupta, Fundamentals of heat exchanger and pressure vessel technology, Hemisphere Publishing, New York, NY, 1986.

[27] Verein Deutscher Ingenieure und Gesellschaft Verfahrenstechnik und Chemieingenieurwesen, VDI-Wärmeatlas, Springer Vieweg, Berlin, 2013.

[28] A. I. Papadopoulos, M. Stijepovic, P. Linke, On the systematic design and selection of optimal working fluids for Organic Rankine Cycles, Applied Thermal Engineering 30 (2010) 760-769. https://doi.org/10.1016/j.applthermaleng.2009.12.006.

[29] A. Desideri, S. Gusev, M. Van den Broek, V. Lemort, S. Quoilin, Experimental comparison of organic fluids for low temperature ORC (organic Rankine cycle) systems for waste heat recovery applications, Energy 97 (2016) 460-469. https://doi.org/10.1016/j.energy.2015.12.012.

[30] N. A. Lai, M. Wendland, J. Fischer, Working fluids for hightemperature organic Rankine cycles, Energy 36 (2011) 199-211. https://doi.org/10.1016/j.energy.2010.10.051.

[31] L. Branchini, A. De Pascale, A. Peretto, Systematic comparison of ORC configurations by means of comprehensive performance indexes, Applied Thermal Engineering 61 (2013) 129-140. https://doi.org/10.1016/j.applthermaleng.2013.07.039.

[32] M. Roedder, M. Neef, C. Laux, K.-P. Priebe, Systematic fluid selection for organic Rankine cycles and performance analysis for a combined high and low temperature cycle, Journal of Engineering for Gas Turbines and Power 138 (2016) 031701. https://doi.org/10.1115/1.4031361.

[33] E. Lemmon, M. Huber, M. McLinden, Reference Fluid Thermodynamic and Transport Properties REFPROP, Version 9.1, National Institute of Standards and Technology, Standard Reference Data Program, Gaithersburg, 2013.

[34] E. W. Lemmon, R. Span, Short fundamental equations of state for 20 industrial fluids, Journal of Chemical \& Engineering Data 51 (2006) 785-850. https://doi.org/10.1021/je050186n. 
[35] P. Colonna, N. Nannan, A. Guardone, E. W. Lemmon, Multiparameter equations of state for selected siloxanes, Fluid Phase Equilibria 244 (2006) 193-211. https://doi.org/10.1016/j.fluid.2006.04.015.

[36] Safety datasheet toluene, Version 1.5, Merck KGaA: Darmstadt, Germany (2017).

[37] Safety datasheet hexamethyldisiloxane, Version 7.0, Merck KGaA: Darmstadt, Germany (2018).

[38] W. C. Andersen, T. J. Bruno, Rapid screening of fluids for chemical stability in organic Rankine cycle applications, Industrial \& Engineering Chemistry Research 44 (2005) 5560-5566. https://doi.org/10.1021/ie050351s.

[39] M. Preißinger, D. Brüggemann, Thermal Stability of Hexamethyldisiloxane (MM) for High-Temperature Organic Rankine Cycle (ORC), Energies 9 (2016) 183. https://doi.org/10.3390/en9030183.

[40] D. Kuhn, M. A. Kholiq, E. Heinzle, B. Bühler, A. Schmid, Intensification and economic and ecological assessment of a biocatalytic oxyfunctionalization process, Green Chemistry 12 (2010) 815-827. https://doi.org/10.1039/B921896C.

[41] B. F. Tchanche, G. Papadakis, G. Lambrinos, A. Frangoudakis, Fluid selection for a low-temperature solar organic Rankine cycle, Applied Thermal Engineering 29 (2009) 2468-2476. https://doi.org/10.1016/j.applthermaleng.2008.12.025.

[42] T. Hung, S. Wang, C. Kuo, B. Pei, K. Tsai, A study of organic working fluids on system efficiency of an ORC using low-grade energy sources, Energy 35 (2010) 1403-1411. https://doi.org/10.1016/j.energy.2009.11.025.

[43] H. Yu, X. Feng, Y. Wang, A new pinch based method for simultaneous selection of working fluid and operating conditions in an ORC (Organic Rankine Cycle) recovering waste heat, Energy 90 (2015) 36-46. https://doi.org/10.1016/j.energy.2015.02.059.

[44] H. Chen, D. Y. Goswami, E. K. Stefanakos, A review of thermodynamic cycles and working fluids for the conversion of low-grade 
heat, Renewable and Sustainable Energy Reviews 14 (2010) 3059-3067. https://doi.org/10.1016/j.rser.2010.07.006.

[45] R. Span, W. Wagner, Equations of State for Technical Applications. II. Results for Nonpolar Fluids, International Journal of Thermophysics 24 (2003) 41-109. https://doi.org/10.1023/A:1022310214958.

[46] M. L. Huber, J. F. Ely, A predictive extended corresponding states model for pure and mixed refrigerants including an equation of state for R134a, International Journal of Refrigeration 17 (1994) 18-31. https://doi.org/10.1016/0140-7007(94)90083-3.

[47] M. Thol, L. Piazza, R. Span, A New Functional Form for Equations of State for Some Weakly Associating Fluids, International Journal of Thermophysics 35 (2014) 783-811. https://doi.org/10.1007/s10765-0141633-1.

[48] Y. Zhou, E. W. Lemmon, Preliminary Helmholtz equation of state for RE245fa2 (2010).

[49] Y. Zhou, E. W. Lemmon, Preliminary Helmholtz equation of state for RE347mcc (2012).

[50] Solkatherm ${ }^{\circledR}$ SES36 High Temperature Working Fluid, Product datasheet, Solvay Fluor GmbH: Hannover, Germany (2015).

[51] D. Luo, A. Mahmoud, F. Cogswell, Evaluation of Low-GWP fluids for power generation with Organic Rankine Cycle, Energy 85 (2015) 481488. https://doi.org/10.1016/j.energy.2015.03.109.

[52] T. F. Stocker, et al., Climate Change 2013: The Physical Science Basis (2013).

[53] B. Gil, J. Kasperski, Performance estimation of ejector cycles using ethers and fluorinated ethers as refrigerants, Applied Thermal Engineering $133 \quad$ (2018) 269-275. https://doi.org/10.1016/j.applthermaleng.2018.01.061.

[54] W. Lewandowski, E. Radziemska, M. Ryms, P. Kubski, Systematic and selection criteria for ORC system working fluid used for a determined amount of excessive energy, Ecological Chemistry and Engineering A 17 (2010) 1493-1503. 
[55] S. Srikanth, B. Ravikumar, S. K. Das, K. Gopalakrishna, K. Nandakumar, P. Vijayan, Analysis of failures in boiler tubes due to fireside corrosion in a waste heat recovery boiler, Engineering Failure Analysis 10 (2003) 59-66. https://doi.org/10.1016/S1350-6307(02)00030-4.

[56] A. Landelle, N. Tauveron, R. Revellin, P. Haberschill, S. Colasson, V. Roussel, Performance investigation of reciprocating pump running with organic fluid for organic Rankine cycle, Applied Thermal Engineering 113 (2017) 962-969. https://doi.org/10.1016/j.applthermaleng.2016.11.096. 


\title{
Supplementary material for: \\ Experimental investigation of a cascaded organic Rankine cycle plant for the utilization of waste heat at high and low temperature levels
}

\author{
Matthias Linnemann ${ }^{\mathrm{a}}$, Klaus-Peter Priebe ${ }^{\mathrm{b}}$, André Heim ${ }^{\mathrm{c}}$, Carsten Wolff ${ }^{\mathrm{b}}$, \\ Jadran Vrabec ${ }^{\mathrm{a}, *}$ \\ ${ }^{a}$ Thermodynamics and Process Engineering, Technical University of Berlin, \\ Ernst-Reuter-Platz 1, 10623 Berlin, Germany \\ ${ }^{b}$ Dortmund University of Applied Sciences and Arts, Otto-Hahn-Straße 23, 44227 \\ Dortmund, Germany \\ ${ }^{c}$ Heim Präzisionstechnik GmbH, Höfenstraße 6, 51645 Gummersbach, Germany
}

\begin{abstract}
This supplementary material provides information about the the employed heat source, boundary conditions, design parameters and the experimental data.
\end{abstract}

\footnotetext{
*Corresponding author

Email address: vrabec@tu-berlin.de (Jadran Vrabec)
} 


\section{Supplementary material.}

Table 1: Parameters of the employed internal combustion engine.

\begin{tabular}{lllll}
\hline Load & 100 & 75 & 50 & $\%$ \\
\hline Electrical power output & 800 & 600 & 400 & $\mathrm{~kW} \pm 8 \%$ \\
Jacket water heat load & 421 & 335 & 258 & $\mathrm{~kW} \pm 8 \%$ \\
Engine coolant volume flow rate & & 10.3 & & $\mathrm{l} / \mathrm{s}$ \\
Exhaust gas heat load & & 378 & 280 & $\mathrm{~kW} \pm 8 \%$ \\
Exhaust gas temperature & 468 & 492 & 519 & ${ }^{\circ} \mathrm{C}$ \\
Exhaust gas mass flow rate & 1.1808 & 0.8956 & 0.6192 & $\mathrm{~kg} / \mathrm{s}$ \\
Fuel consumption & 1916 & 1479 & 1047 & $\mathrm{~kW}+5 \%$ \\
Electrical efficiency & 41.8 & 40.6 & 38.2 & $\%$ \\
\hline
\end{tabular}

a Assuming a cooling to $120^{\circ} \mathrm{C}$. 
Table 2: CORC design results with heat source boundary conditions.

\begin{tabular}{|c|c|c|c|c|c|c|c|c|c|}
\hline \multicolumn{5}{|c|}{$\begin{array}{l}\text { HT-ORC toluene } \\
\dot{m}=0.56 \mathrm{~kg} / \mathrm{s} \\
\text { Evaporation: } T_{s}=250.0^{\circ} \mathrm{C} ; p_{s}=16.72 \mathrm{bar} \\
\text { Condensation: } T_{s}=110.5^{\circ} \mathrm{C} ; p_{s}=1.01 \mathrm{bar}\end{array}$} & \multicolumn{5}{|c|}{$\begin{array}{l}\text { Exhaust gas } \\
\dot{m}_{\mathrm{A}}=0.9 \mathrm{~kg} / \mathrm{s} \\
\dot{m}_{\mathrm{B}, \mathrm{D}}=1.3 \mathrm{~kg} / \mathrm{s}\end{array}$} \\
\hline \multirow[t]{2}{*}{ Point } & $T$ & $p$ & $h$ & $s$ & Point & $T$ & $p$ & $h$ & $s$ \\
\hline & ${ }^{\circ} \mathrm{C}$ & bar & $\mathrm{kJ} / \mathrm{kg}$ & $\mathrm{kJ} / \mathrm{kgK}$ & & ${ }^{\circ} \mathrm{C}$ & bar & $\mathrm{kJ} / \mathrm{kg}$ & $\mathrm{kJ} / \mathrm{kgK}$ \\
\hline 1 & 102.0 & 17.80 & -15.97 & -0.048 & $\mathrm{~A}$ & 492.0 & 1.01 & 1015.94 & 7.44 \\
\hline 2 & 155.0 & 17.78 & 93.57 & 0.225 & B & 381.8 & 1.01 & 886.64 & 7.26 \\
\hline 3 & 255.0 & 17.10 & 564.53 & 1.168 & $\mathrm{C}$ & 191.5 & 1.01 & 673.40 & 6.88 \\
\hline 4 & 253.0 & 16.72 & 561.46 & 1.163 & $\mathrm{D}$ & 120.0 & 1.01 & 595.72 & 6.70 \\
\hline 5 & 185.9 & 1.01 & 482.55 & 1.229 & \multirow{2}{*}{\multicolumn{5}{|c|}{$\begin{array}{l}\text { CC ethylene glycol + water } \\
\dot{m}=5.2 \mathrm{~kg} / \mathrm{s}\end{array}$}} \\
\hline 6 & 118.7 & 1.01 & 372.94 & 0.972 & & & & & \\
\hline 7 & 99.0 & 1.01 & -22.97 & -0.061 & \multicolumn{5}{|c|}{$\bar{c}_{p}=3.70 \mathrm{~kJ} / \mathrm{kgK}$} \\
\hline \multicolumn{5}{|c|}{$\begin{array}{l}\text { LT-ORC SES36 } \\
\dot{m}=3.34 \mathrm{~kg} / \mathrm{s}\end{array}$} & Point & $\begin{array}{c}{ }^{T} \\
{ }^{\circ} \mathrm{C}\end{array}$ & $\begin{array}{c}p \\
\text { bar }\end{array}$ & & \\
\hline \multirow{2}{*}{\multicolumn{5}{|c|}{$\begin{array}{l}\text { Evaporation: } T_{s}=76.5^{\circ} \mathrm{C} ; p_{s}=3.50 \mathrm{bar} \\
\text { Condensation: } T_{s}=35.6^{\circ} \mathrm{C} ; p_{s}=1.01 \mathrm{bar}\end{array}$}} & $\mathrm{J}$ & 90.0 & 3.0 & & \\
\hline & & & & & $\mathrm{K}$ & 80.2 & 3.0 & & \\
\hline Point & $\begin{array}{l}\mathrm{T} \\
{ }^{\circ} \mathrm{C}\end{array}$ & $\begin{array}{c}p \\
\text { bar }\end{array}$ & $\begin{array}{c}h \\
\mathrm{~kJ} / \mathrm{kg}\end{array}$ & $\begin{array}{c}s \\
\mathrm{~kJ} / \mathrm{kgK}\end{array}$ & \multicolumn{5}{|c|}{$\begin{array}{l}\text { IC } \quad \text { ethylene glycol + water } \\
\dot{m}=4.2 \mathrm{~kg} / \mathrm{s}\end{array}$} \\
\hline I & 30.3 & 3.50 & 231.03 & 1.105 & \multicolumn{5}{|c|}{$\bar{c}_{p}=3.70 \mathrm{~kJ} / \mathrm{kgK}$} \\
\hline II & 57.4 & 3.50 & 259.12 & 1.197 & \multirow[t]{2}{*}{ Point } & $T$ & $p$ & & \\
\hline III & 87.0 & 3.50 & 410.74 & 1.625 & & ${ }^{\circ} \mathrm{C}$ & bar & & \\
\hline IV & 87.0 & 3.50 & 410.74 & 1.625 & $\mathrm{E}$ & 75.3 & 3.0 & & \\
\hline $\mathrm{V}$ & 67.6 & 1.01 & 396.11 & 1.635 & $\mathrm{~F}$ & 87.4 & 3.0 & & \\
\hline VI & 37.7 & 1.01 & 367.91 & 1.546 & $\mathrm{G}$ & 93.7 & 3.0 & & \\
\hline \multirow[t]{2}{*}{ VII } & 29.5 & 1.01 & 230.15 & 1.1028 & $\mathrm{H}$ & 108.0 & 3.0 & & \\
\hline & & & & & I & 75.3 & 3.0 & & \\
\hline
\end{tabular}

${ }^{a}$ Employing thermodynamic properties given by Solvay. 
Table 3: Operational parameters of the HT-ORC test, where the LT-ORC was used to discharge the heat. Note that state points III-VI were in vapor-liquid state.

\begin{tabular}{|c|c|c|c|c|c|c|c|c|c|}
\hline \multicolumn{5}{|c|}{$\begin{array}{l}\text { HT-ORC toluene } \\
\dot{m}=0.51 \mathrm{~kg} / \mathrm{s} \\
\text { Evaporation: } T_{s}=255.5^{\circ} \mathrm{C} ; p_{s}=18.10 \mathrm{bar} \\
\text { Condensation: } T_{s}=130.1^{\circ} \mathrm{C} ; p_{s}=1.70 \mathrm{bar}\end{array}$} & \multicolumn{5}{|c|}{$\begin{array}{l}\text { Exhaust gas } \\
\dot{m}_{\mathrm{A}}=0.88 \mathrm{~kg} / \mathrm{s} \\
\dot{m}_{\mathrm{B}, \mathrm{D}}=1.21 \mathrm{~kg} / \mathrm{s}\end{array}$} \\
\hline \multirow[t]{2}{*}{ Point } & $T$ & $p$ & $h$ & $s$ & Point & $T$ & $p$ & $h$ & $s$ \\
\hline & ${ }^{\circ} \mathrm{C}$ & bar & $\mathrm{kJ} / \mathrm{kg}$ & $\mathrm{kJ} / \mathrm{kgK}$ & & ${ }^{\circ} \mathrm{C}$ & bar & $\mathrm{kJ} / \mathrm{kg}$ & $\mathrm{kJ} / \mathrm{kgK}$ \\
\hline 1 & 96.7 & 19.59 & -26.22 & -0.076 & $\mathrm{~A}$ & 489.2 & 1.01 & 1012.62 & 7.44 \\
\hline 2 & 184.7 & 19.37 & 159.90 & 0.374 & B & 392.0 & 1.01 & 898.90 & 7.28 \\
\hline 3 & 261.7 & 18.07 & 576.32 & 1.186 & $\mathrm{C}$ & 218.1 & 1.01 & 702.64 & 6.94 \\
\hline 4 & 258.1 & 17.20 & 571.40 & 1.180 & $\mathrm{D}$ & 128.8 & 1.01 & 605.21 & 6.72 \\
\hline 5 & 204.0 & 1.56 & 513.02 & 1.256 & \multirow[t]{3}{*}{$\mathrm{CC}$} & \multirow{3}{*}{\multicolumn{4}{|c|}{ shut down in this test }} \\
\hline 6 & 128.8 & 1.71 & 326.90 & 0.813 & & & & & \\
\hline 7 & 93.8 & 1.71 & -33.06 & -0.088 & & & & & \\
\hline \multicolumn{5}{|c|}{$\begin{array}{l}\text { LT-ORC SES } 36^{\mathrm{a}} \\
\dot{m}=3.93 \mathrm{~kg} / \mathrm{s} \\
\text { Evaporation: } T_{s}=89.6^{\circ} \mathrm{C} ; p_{s}=4.91 \mathrm{bar} \\
\text { Condensation: } T_{s}=66.6^{\circ} \mathrm{C} ; p_{s}=2.66 \mathrm{bar}\end{array}$} & \multicolumn{5}{|c|}{$\begin{array}{l}\text { IC } \quad \text { ethylene glycol + water } \\
\dot{m}=3.8 \mathrm{~kg} / \mathrm{s} \\
\bar{c}_{p}=3.70 \mathrm{~kJ} / \mathrm{kgK}\end{array}$} \\
\hline \multirow[t]{2}{*}{ Point } & $T$ & $p$ & $h$ & $s$ & Point & $T$ & $p$ & & \\
\hline & ${ }^{\circ} \mathrm{C}$ & bar & $\mathrm{kJ} / \mathrm{kg}$ & $\mathrm{kJ} / \mathrm{kgK}$ & & ${ }^{\circ} \mathrm{C}$ & bar & & \\
\hline I & 61.2 & 5.60 & 267.61 & 1.221 & $\mathrm{~F}$ & 83.3 & 3.0 & & \\
\hline II & 64.4 & 5.50 & 271.47 & 1.233 & $\mathrm{~F}$ & 83.3 & 3.0 & & \\
\hline III & 89.6 & 4.91 & 347.32 & 1.444 & $\mathrm{G}$ & 91.5 & 3.0 & & \\
\hline IV & 89.6 & 4.91 & 347.32 & 1.444 & $\mathrm{H}$ & 104.5 & 3.0 & & \\
\hline $\mathrm{V}$ & 66.6 & 2.66 & 347.32 & 1.450 & $\mathrm{I}$ & 83.3 & 3.0 & & \\
\hline VI & 66.6 & 2.66 & 343.45 & 1.440 & & & & & \\
\hline VII & 60.6 & 2.66 & 266.83 & 1.220 & & & & & \\
\hline
\end{tabular}

${ }^{a}$ Employing thermodynamic properties determined with a preliminary EOS in REFPROP. 
Table 4: Operational parameters of the LT-ORC test.

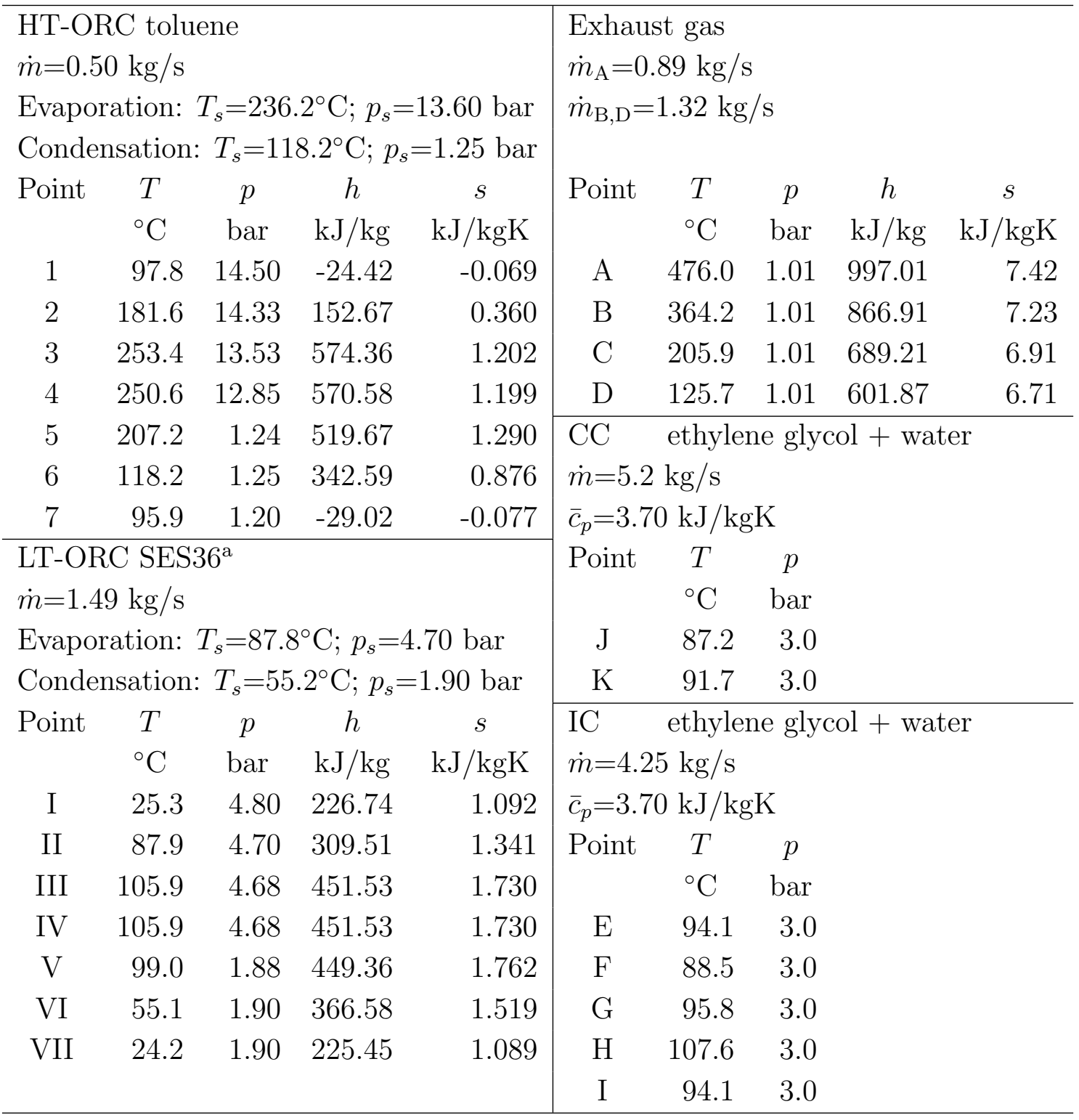

a Employing thermodynamic properties determined with a preliminary EOS in REFPROP. 